\title{
Recent Developments in Ultra High Temperature Ceramics at NASA Ames
}

\author{
Sylvia M. Johnson, ${ }^{*}$ Matt Gasch, ${ }^{\dagger}$ and John W. Lawson ${ }^{*}$ \\ NASA Ames Research Center, Moffett Field, CA 94035 \\ and \\ Michael I. Gusman ${ }^{\S}$ and Margaret M. Stackpoole ${ }^{* *}$ \\ ELORET Corp., 465 S. Mathilda Avenue, Suite 103, Sunnyvale, CA 94086
}

\begin{abstract}
NASA Ames is pursuing a variety of approaches to modify and control the microstructure of UHTCs with the goal of improving fracture toughness, oxidation resistance and controlling thermal conductivity. The overall goal is to produce materials that can perform reliably as sharp leading edges or nose tips in hypersonic reentry vehicles. Processing approaches include the use of preceramic polymers as the $\mathrm{SiC}$ source (as opposed to powder techniques), the addition of third phases to control grain growth and oxidation, and the use of processing techniques to produce high purity materials. Both hot pressing and field assisted sintering have been used to make UHTCs. Characterization of the mechanical and thermal properties of these materials is ongoing, as is arcjet testing to evaluate performance under simulated reentry conditions. The preceramic polymer approach has generated a microstructure in which elongated $\mathrm{SiC}$ grains grow in the form of an in-situ composite. This microstructure has the advantage of improving fracture toughness while potentially improving oxidation resistance by reducing the amount and interconnectivity of $\mathrm{SiC}$ in the material. Addition of third phases, such as $\mathrm{Ir}$, results in a very fine-grained microstructure, even in hot-pressed samples. The results of processing and compositional changes on microstructure and properties are reported, along with selected arcjet results.
\end{abstract}

\section{Nomenclature}

$\dot{q}_{\text {conv }} \quad=$ convective heat flux

$\dot{q}_{\text {rad }} \quad=$ radiative heat flux

$\dot{q}_{\text {cond }}=$ conductive heat flux

\section{Introduction}

$\mathrm{U}$ ltra high temperature ceramics (UHTCs) comprise materials in the diboride, carbide, nitride families of hafnium, zirconium and tantalum. They are so called because of their very refractory nature, making them capable of use at temperatures above those possible for ceramics like silicon nitride and carbide. For example, HfB2 has a melting point of $\sim 3300{ }^{\circ} \mathrm{C} .{ }^{1}$ In addition, UHTCs are very hard, have good wear resistance and mechanical strength, and have relatively high thermal conductivities (compared to other ceramic materials). Because of these attributes, UHTCs are ideal for use in thermal protection systems, especially those that require chemical and structural stability at extremely high operating temperatures. UHTCs have the potential to revolutionize the

\footnotetext{
* Chief Materials Technologist, Entry Systems \& Technology Division M/S 234-1

${ }^{\dagger}$ Materials Engineer, Thermal Protection Materials Branch, M/S 234-1

* Computer Scientist, Thermal Protection Materials Branch, M/S 234-1

$\S$ Senior Research Scientist, Thermal Protection Materials Branch, M/S 234-1

** Senior Research Scientist, Thermal Protection Materials Branch, M/S 234-1
} 
aerospace industry by enabling the development of sharp hypersonic vehicles or atmospheric entry probes capable of the most extreme entry conditions.

Energy at a UHTC sharp leading edge is managed by conduction through the materials and re-radiation from a cooler surface, as illustrated schematically in Figure $1 .{ }^{2}$ The properties of most interest for the application are therefore high thermal conductivity (especially controlled and/or tailorable in specific directions), high fracture toughness and mechanical strength, especially at elevated temperatures, and good oxidation resistance in reentry conditions. Strong covalent bonding is responsible for the high melting points, moduli, and hardness of the UHTC family of materials. ${ }^{3-4}$ High negative free energies of formation also give UHTCs excellent chemical and thermal stability under many conditions. Compared to carbides and nitrides, the diborides tend to have higher thermal conductivity, which gives them good thermal shock resistance and makes them ideal for many high temperature thermal applications. ${ }^{5}$

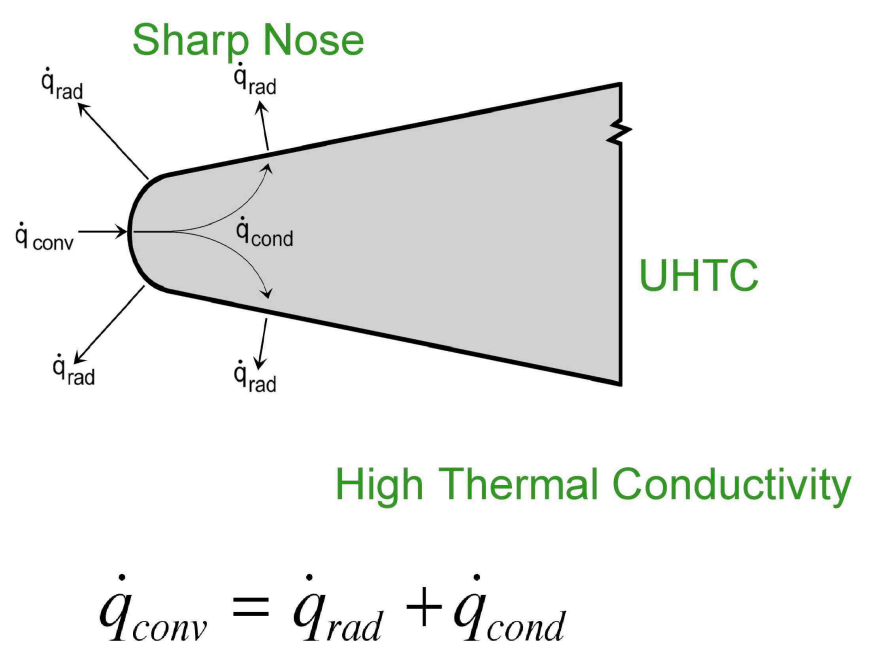

Figure 1. Temperature constraints at the sharp leading edge

This paper discusses some early uses of UHTC materials at NASA and then considers issues being currently addressed in materials development. Some recent progress on overcoming the perceived drawbacks of UHTCs and in making composite structures rounds out this discussion.

\section{Background}

UHTCs originated in the early 1960s. Some of the earliest and most thorough work to date was performed then by the company ManLabs, under a research program funded by the Air Force Materials Laboratory (AFML) ${ }^{6-7}$ Work on UHTCs was initiated to meet the need for high temperature materials that would allow the development of maneuverable hypersonic flight vehicles. Since then, despite research progress, several significant challenges remain in the use of UHTCs, and these materials have yet to be widely implemented.

Bulk UHTCs are fabricated at temperatures ranging from $1900-2100{ }^{\circ} \mathrm{C}$ and pressures of $60-100 \mathrm{MPa}$ by hot pressing in either resistance- or induction-heated furnaces, using graphite dies — in processes that have not changed much since the 1960s. High melting temperatures make consolidating pure samples by conventional hot pressing extremely difficult. Work by ManLabs found that additives could eliminate billet cracking and make dense, finegrained microstructures achievable. ${ }^{6}$ In particular, adding $\mathrm{SiC}$ from 5-30 volume percent improved UHTC densification and oxidation resistance.

An example of today's state-of-the-art UHTC/SiC composite is shown in Figure 2. The gray areas are $\mathrm{HfB}_{2}$ grains and the black areas are $\mathrm{SiC}$ grains. 


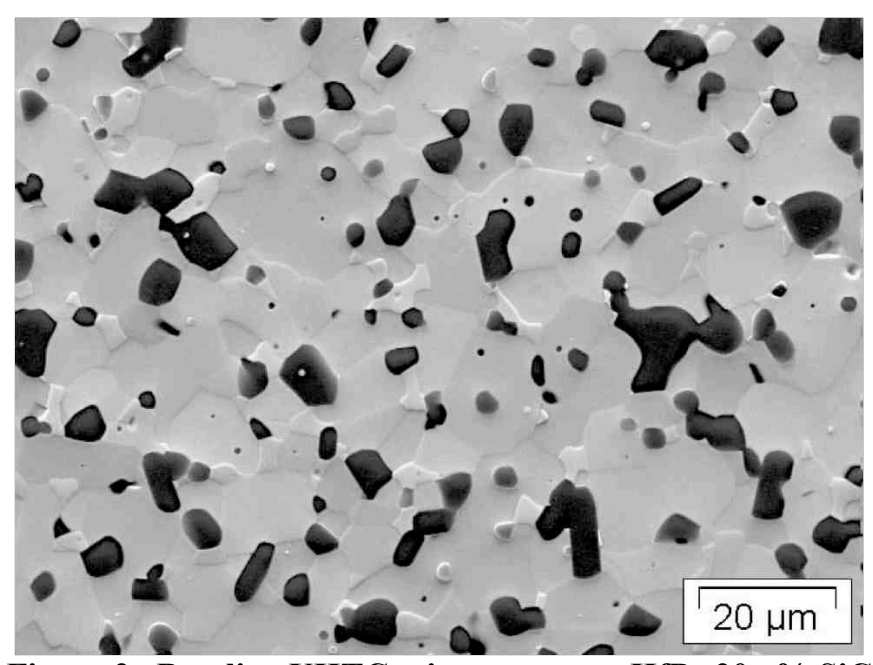

Figure 2. Baseline UHTC microstructure $\mathrm{HfB}_{2}-20$ v\% SiC

Research on UHTCs slowed considerably after the work by ManLabs ended, until the early 1990s, when interest in monolithic UHTC materials renewed. High costs of raw materials, in addition to the high temperatures and pressures required to hot press UHTC powders, have led to new investigations into alternate ways of fabricating UHTCs. In addition to conventional methods, researchers are looking at reactive hot pressing and pressureless sintering by liquid infiltration and reaction. ${ }^{8-9}$ These new reaction-based processes share the near-net shape and nearnet dimension capabilities of gas-phase reaction bonding, as well as reduced processing temperatures and times required for solid state sintering.

Basic property evaluation of UHTCs and UHTC composites is being conducted at a number of government facilities within NASA and the military, as well as at some universities. ${ }^{10,11,12,13,14}$ With this resurgence in basic research, UHTC carbides and nitrides are getting attention, as new processing techniques make the fabrication of these materials easier.

NASA Ames began working on UHTCs in the early 1990s, and in 1997 and 2000, in collaboration with the Air Force and Sandia National Labs, NASA conducted two flight experiments, SHARP-B1 and SHARP-B2 (Sharp $\boldsymbol{H}$ ypersonic $\boldsymbol{A}$ ero-thermodynamic $\boldsymbol{R}$ esearch $\boldsymbol{P r o b e s}$ ). These experiments briefly exposed the UHTC materials to actual reentry environments. ${ }^{15}$ The SHARP-B1 vehicle tested a $\mathrm{HfB}_{2}-\mathrm{SiC}$ nose tip with a $3.5 \mathrm{~mm}$ radius. The SHARP-B1 vehicle was not recovered, by design, and thus post-test characterization of the UHTCs was not possible. The test vehicles and location of the UHTC parts are shown in Figure 3.
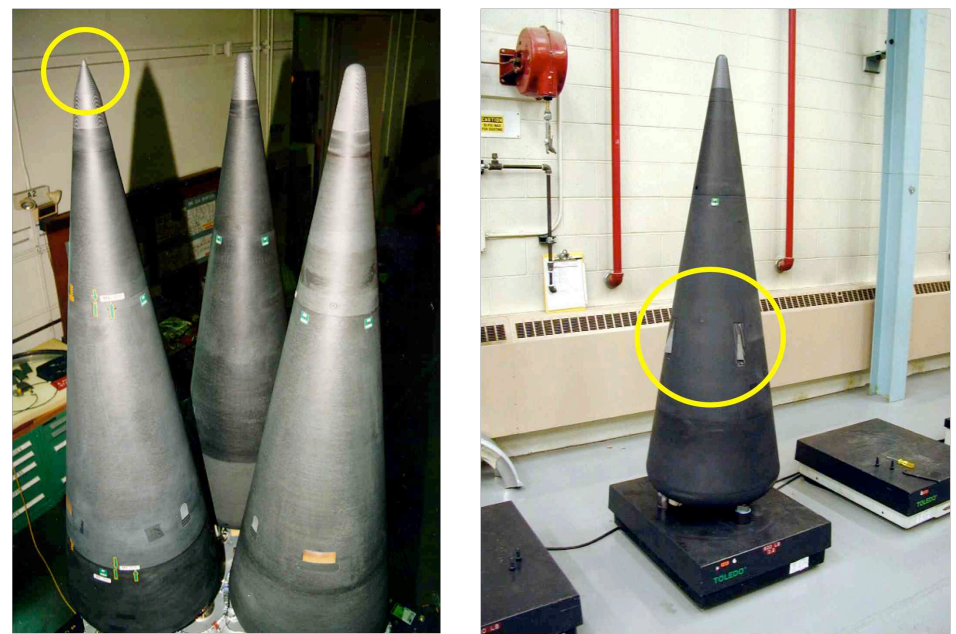

Figure 3. Flight hardware: SHARP-B1 May 21, 1997 (left) and SHARP-B2 Sept. 28, 2000 (right) 
The second vehicle, SHARP-B2, was recovered. This test flew four segmented strakes on the exterior of the reentry vehicle. The strakes were designed to retract within the reentry vehicle at a predetermined altitude, after which a parachute was deployed, allowing the vehicle and UHTC materials to be retrieved. Each UHTC strake comprised three segments, each a different UHTC material $\left(\mathrm{HfB}_{2}\right.$ or $\left.\mathrm{ZrB}_{2}\right)$, as shown in Figure 4. The flight experiment was a success, but post-flight examination of the recovered materials revealed inadequate development had yielded materials with poor mechanical properties, that is, with large agglomerates, and a number of strake segments failed. ${ }^{16}$ NASA Ames has continued to experiment with these materials and has made progress in improving processing methodologies and resulting material properties, as discussed.

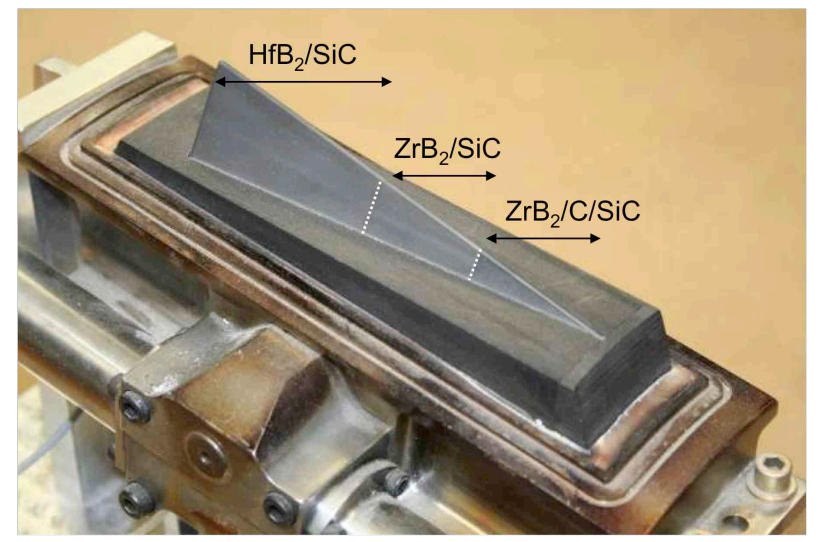

Figure 4. The strakes were composed of three sections, each having a different UHTC composition.

Under funding from NASA's Fundamental Aeronautics Program (FAP), (Hypersonics Project) NASA Ames has pursued a variety of approaches to modifying and controlling the microstructure of UHTCs and improving fracture toughness and oxidation resistance while controlling thermal conductivity.

The goal of the FAP is long-term multidisciplinary investment in critical research in aeronautics technology, with research tied to tool development, not to a specific vehicle or mission.

\section{Research in UHTCs}

Ames is continuing to pursue a variety of approaches to modify and control the microstructure of UHTCs with these aims. The overall goal is to produce materials that can perform reliably as sharp leading edges or nose tips in hypersonic reentry vehicles. The focus has been on materials in the hafnium diboride family, with a baseline material of $\mathrm{HfB}_{2} / \mathrm{SiC}$ composite with $20 \%$ vol. content of $\mathrm{SiC}\left(\mathrm{HFB}_{2} / 20 \mathrm{vol} \% \mathrm{SiC}\right)$. This baseline was selected during a previous program (Space Launch Initiative) based on the data from ManLabs and the desire to use the material with the highest melting point.

Recent research can be divided into efforts to control the following material characteristics:

- Efforts to control grain size, through additives (Ir additions) and processing by field-assisted sintering (FAS)

- Efforts in the control of grain shape through the addition of preceramic polymers and the use of particle coatings (fluidized bed CVD)

- Efforts at establishing purity of grain boundaries with the addition of preceramic polymers, by processing (fluidized bed CVD) and by self-propagating reactions

- Control of oxide formation, including increasing oxide stability/emissivity with additives and reducing amount of $\mathrm{SiC}$

Some of the efforts to control grain size, grain shape, and oxide formation will be discussed here. In all cases, the goal is to improve the mechanical properties, especially fracture toughness, control thermal conductivity, and improve oxidation resistance.

\section{A. Control of grain size}

Grain size in ceramics has a substantial influence on properties, especially strength. Strength increases as the inverse square of the grain size, and thus considerable advantage in mechanical strength can be obtained by reducing grain size. ${ }^{17}$ Grain size depends on initial particle size of powders and on additives, processing time, and temperature. UHTCs have traditionally been prepared by hot pressing, usually requiring high temperatures, in excess 
of $2000{ }^{\circ} \mathrm{C}$ and of long duration. Spark plasma sintering (or field assisted sintering) allows for consolidation in much shorter intervals and sometimes lower temperatures, with the resultant grain size being much reduced.

The addition of phases that can limit grain growth — by mechanisms such as grain boundary pinning - is an alternative approach to obtaining fine-grained microstructures. Iridium is added to the powders in various quantities, and powders are consolidated by both techniques.

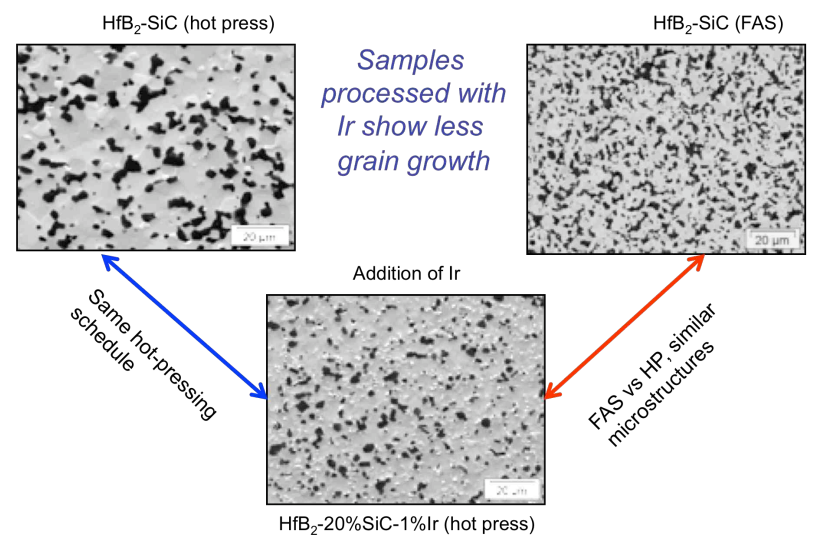

Figure 5. Controlling grain size by additives or processing

Figure 5 compares the microstructure formed by hot pressing with that formed by field-assisted sintering (FAS) and by hot pressing powders with the addition of Ir. FAS reduces the grain size of the baseline material from an average of $7.7 \mu \mathrm{m}$ to $\sim 4.1 \mu \mathrm{m}$. The addition of Ir results in a microstructure formed by hot pressing that is very similar to that formed by FAS. The effect on hardness and toughness, both measured by indentation, is shown in Table 1. Although the data set is limited, and the results need to be confirmed with large samples by different techniques, the indication is that a substantial increase $(\sim 25 \%)$ in toughness can be achieved by the addition of Ir to the baseline materials.

\section{Table 1. Hardness and fracture toughness increase with processing (shorter times) and additional phases (Ir and $\mathrm{TaSi}_{2}$ )}

\begin{tabular}{|ccc|}
\hline Material & $\begin{array}{c}\text { Hardness } \\
\mathbf{G P a}\end{array}$ & $\begin{array}{c}\text { Toughness } \\
\mathbf{M P a}^{*} \mathbf{m}^{1 / 2}\end{array}$ \\
\hline $\begin{array}{c}\text { Baseline UHTC } \\
\text { (long process) } \\
\text { UHTC }+ \text { Ir }\end{array}$ & $16.5 \pm 0.2$ & $4.3 \pm 0.6$ \\
& $18.2 \pm 0.1$ & $5.6 \pm 0.3$ \\
\hline
\end{tabular}

\section{B. Control of grain shape}

Control of grain shape, especially the growth of an in-situ toughening phase, is one means of increasing fracture toughness. Two approaches have been taken (see below); the addition of preceramic polymers as the SiC source is the one that we will discuss here.

- Adding preceramic polymers as $\mathrm{SiC}$ source, growing acicular $\mathrm{SiC}$ grains, and potentially improving mechanical properties with reduced amount of $\mathrm{SiC}$ (changes crack path and improves toughness) and oxidation behavior

- Use of particle coatings (fluidized bed CVD) to grow acicular SiC grains and maintain clean grain boundaries

Conventionally, silicon carbide is added to the $\mathrm{HfB}_{2}$ as a powder, and the two powders are milled together to reduce particle size. An alternative is to add $\mathrm{SiC}$ as a preceramic polymer. Preceramic polymers have been used extensively in ceramic processing for the past 25 years. As they are usually liquids, they can be distributed by methods other than milling, and they tend to coat the powders rather than being present as discrete particles. On heat treatment, the polymer loses its organic constituents and converts to a ceramic phase, and the resulting $\mathrm{SiC}$ material forms along the grain boundaries, appearing as rods or acicular particles. These rods are illustrated in Figure 6, 
which shows the effects of increasing amounts of preceramic polymer on the number and size of the acicular grains. The acicular grains appear to be uniformly distributed three-dimensionally in the microstructure. Increasing the amount of polymer affects the number and thickness of the rod-like grains, but not the length. This observation is consistent with the concept of the grains growing from polymer originally deposited on the surface of particles and forming $\mathrm{SiC}$ at the resultant grain boundaries.

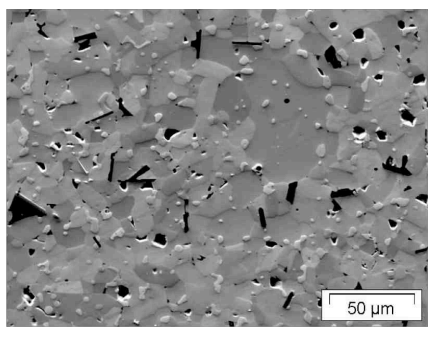

$5 \% * \mathrm{SiC}$

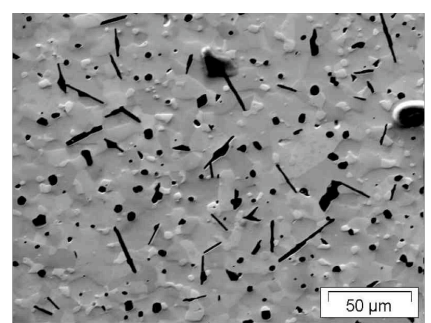

$10 \% * \mathrm{SiC}$

Rod diameter $\sim 2 \mu \mathrm{m}$

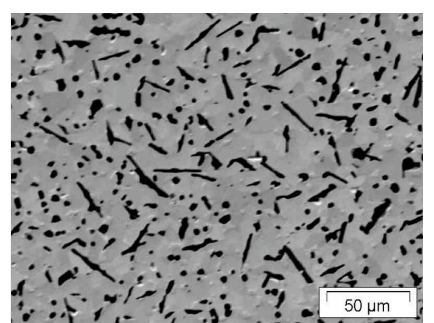

$15 \% * \mathrm{SiC}$

Rod diameter $\sim 5 \mu \mathrm{m}$

Figure 6. Additives as preceramic polymer: Samples processed with 5 to $>20$ volume $\% \mathrm{SiC}$

Examination of the crack path formed by indentation cracks indicates that the acicular grains do deflect cracks, and preliminary measures of fracture toughness demonstrate a steady improvement with increasing $\mathrm{SiC}$ content.
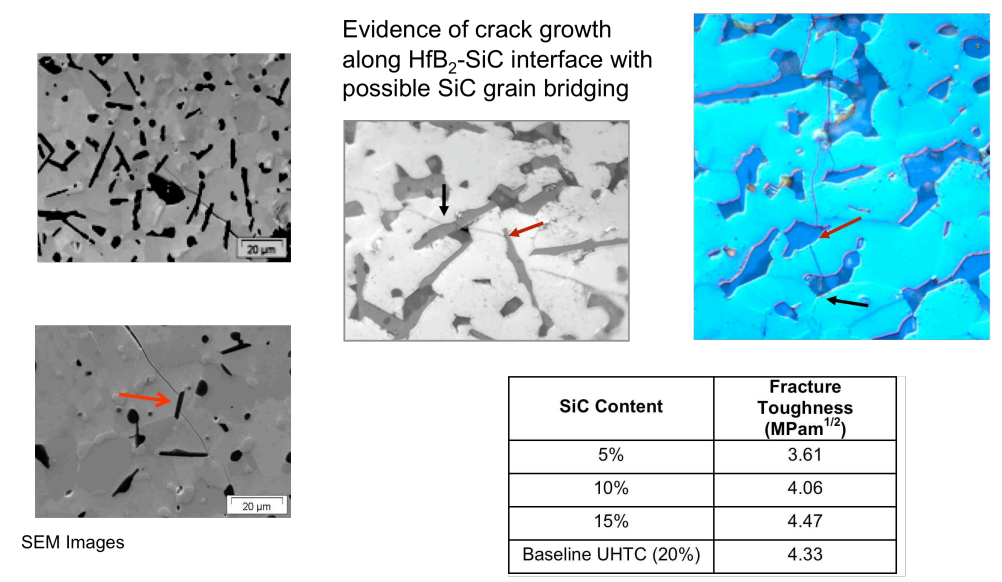

Figure 7. High-aspect-ratio $\mathrm{SiC}$ increases toughness for a given $\mathrm{SiC}$ loading (Optical Images courtesy Paul Becher, ORNL)

An additional advantage of the preceramic polymer approach is the improved mechanical properties and reduction in the amount of $\mathrm{SiC}$. $\mathrm{SiC}$ oxidizes preferentially in UHTCs, and in arcjet tests, where the heating is essentially one dimensional, the $\mathrm{SiC}$ depletes to some distance below the surface oxide. Reducing the amount of $\mathrm{SiC}$ and its connectivity may reduce this depletion zone by limiting pathways for oxygen to diffuse in and react.

\section{Control of oxide formation}

The oxidation resistance of UHTCs during reentry is a major drawback in the use of these materials. The simulation of reentry by arcjet testing results in the formation of an outer oxide layer on top of a zone that is depleted in $\mathrm{SiC}$. 


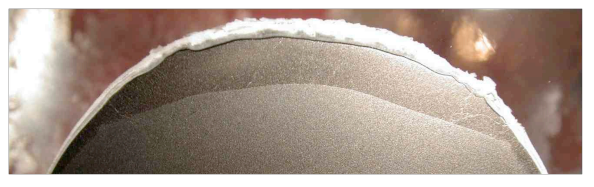

Figure 8. Reducing oxide formation

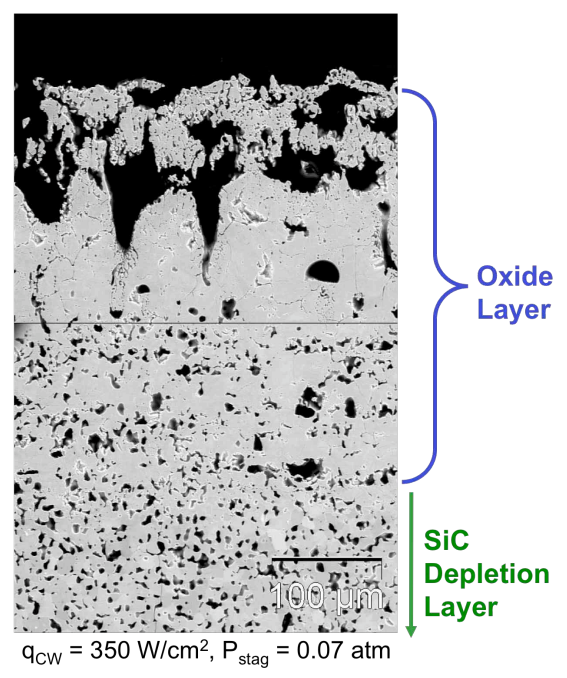

The exact thickness and phase composition of the oxide is related to the arcjet conditions and whether $\mathrm{SiC}$ is being actively or passively oxidized. However, oxidation can be effectively decreased in a wide variety of conditions. Approaches to control the oxidation include the reduction in the amount of $\mathrm{SiC}$, as discussed, reduction in the grain size, and the addition of a third phase. Additional phases may reduce grain size, as Ir does, or change the color of the oxide layer, as is the effect of $\mathrm{TaSi}_{2}$. Although UHTCs are dark and have a relatively high emissivity, hafnium oxide is white or light in color, and thus formation of an oxide layer results in a decrease in emissivity. Forming a darker oxide can improve this emissivity; previous work by Schüßler et al. shows this effect. ${ }^{18}$

Both Ir and $\mathrm{TaSi}_{2}$ were added to the baseline material separately and together. As noted, Ir resulted in a net grain-size reduction, while the addition of $\mathrm{TaSi}_{2}$ results in grain size increase in the hot pressed material but not in the FAS material. Microstructures and average grain sizes for materials consolidated by the two techniques are shown in Figure 9.
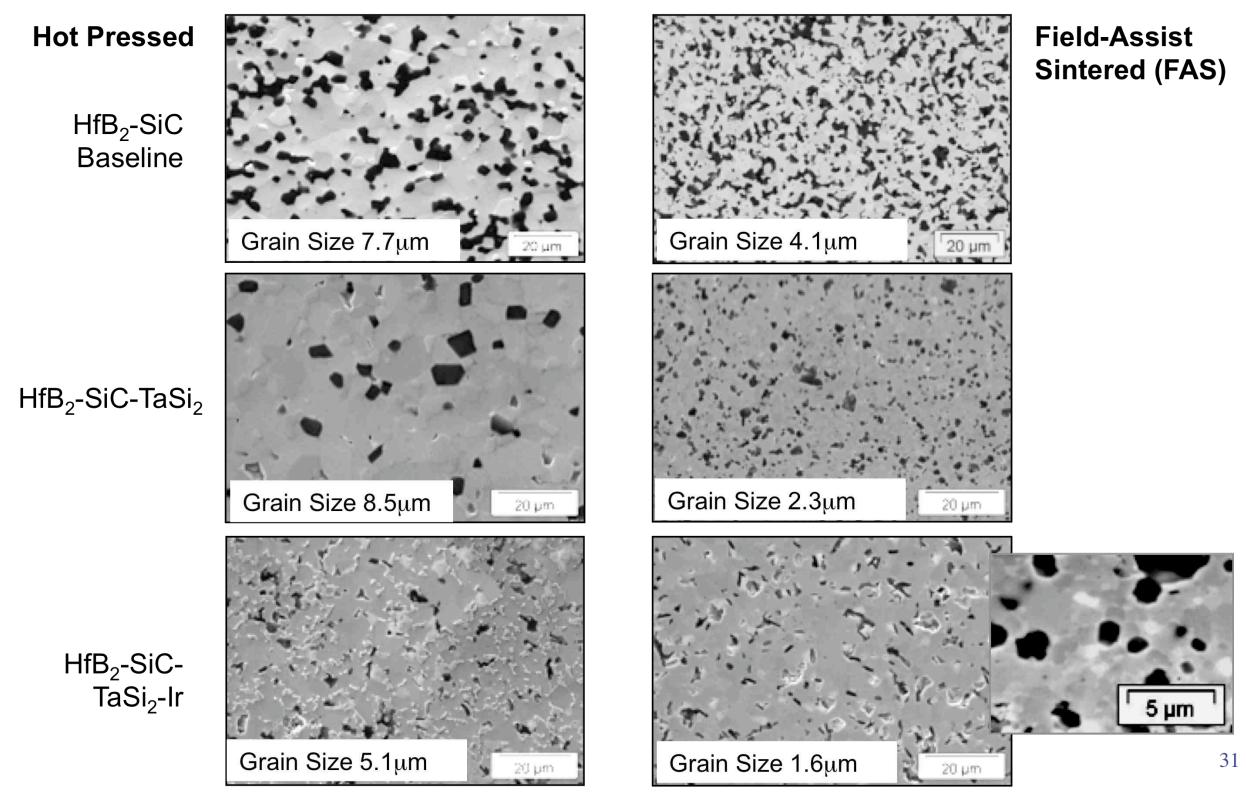

Figure 9. Physical characterization: microstructure

The difference in the two sintering techniques accounts for the differences in microstructure. The long durations at temperature in hot pressing allow for grain growth and diffusion of third phases. In FAS, the durations are very short and diffusion is kept to a minimum. The addition of a third phase may reduce diffusion along grain boundaries 
and result in less grain growth. Iridium appears to be discrete particles located at grain boundaries and at triple points and may act to pin grain boundaries and inhibit sintering. The addition of $\mathrm{TaSi}_{2}$ alone in hot pressing increases grain size, probably because of the formation of grain boundary phases, most likely of a glassy nature, which promote diffusion, sintering, and grain growth. These phases do not have time to form and distribute in FAS. Iridium does not form in these phases and thus acts to pin the grains and reduce the grain size in both cases.

The effect on the oxidized materials is significant. Flat-faced arcjet models of $2.5 \mathrm{~cm}$ diameter were tested in the Aerodynamic Heating Facility (AHF) at Ames. The models were sectioned after testing and the thicknesses of the layers were measured. The cross sections are shown in Figure 10 and the conditions and thicknesses are tabulated in Table 2.

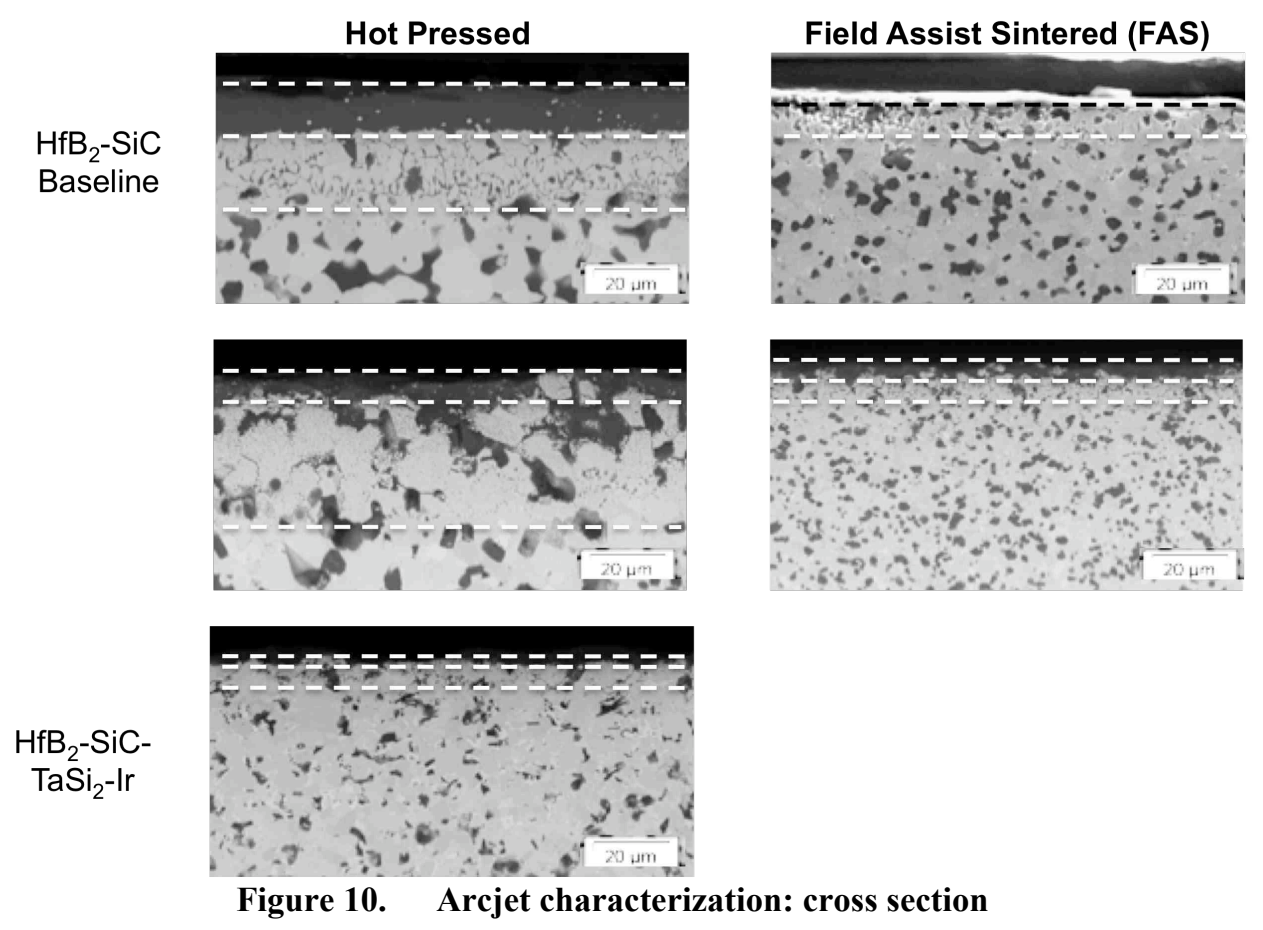

Table 2. Arcjet characterization: summary, oxidation resistance

\begin{tabular}{|l|l|c|c|c|c|c|}
\hline \multicolumn{1}{|c|}{ Model ID } & \multicolumn{1}{|c|}{$\begin{array}{c}\text { Sinter } \\
\text { Method }\end{array}$} & $\begin{array}{c}\text { Heat Flux } \\
\left(\mathbf{W} / \mathbf{c m}^{2}\right)\end{array}$ & $\begin{array}{c}\text { Pstag } \\
(\mathbf{a t m})\end{array}$ & $\begin{array}{c}\text { Duration } \\
(\mathbf{s e c})\end{array}$ & $\begin{array}{c}\text { Oxide Layer } \\
(\boldsymbol{\mu m})\end{array}$ & $\begin{array}{c}\text { SiC Depletion } \\
(\boldsymbol{\mu m})\end{array}$ \\
\hline $\begin{array}{l}\mathrm{HfB} \\
(\mathrm{Baseline})\end{array}$ & Hot Press & 300 & 0.19 & 600 & 13 & 24 \\
\hline $\mathrm{HfB}_{2}-\mathrm{SiC}$ & FAS & 250 & 0.10 & 600 & 3 & 8 \\
\hline $\mathrm{HfB}_{2}-\mathrm{SiC}-\mathrm{TaSi}_{2}$ & Hot Press & 250 & 0.10 & 600 & 7 & 34 \\
\hline $\mathrm{HfB}_{2}-\mathrm{SiC}-\mathrm{TaSi}_{2}$ & FAS & 250 & 0.10 & 600 & 3 & 6 \\
\hline $\mathrm{HfB}_{2}-\mathrm{SiC}-\mathrm{TaSi}_{2}-\mathrm{Ir}$ & Hot Press & 250 & 0.10 & 600 & 4 & 9 \\
\hline
\end{tabular}

The addition of Ta improves the oxidation resistance of the material made by either technique, as shown by the relative sizes of the zones. Although one could potentially ascribe this effect to increased emissivity, preliminary emittance measurements do not provide evidence for that, and further study is needed. The existence of a much thicker depletion zone in the hot-pressed material can be attributed to the formation and distribution of a grain boundary phase that allows for more rapid diffusion of $\mathrm{O}$. 
The addition of Ir seems to decrease both the oxide and depletion zones in the hot-pressed material (the FAS material was not tested). This can be associated with the much smaller grain size and thus potentially more or thinner grain boundary phases and more convoluted pathways for $\mathrm{O}$ diffusion.

\section{Future Work}

Formation of fiber-reinforced composites seems to be an attractive way to improve the properties of monolithic ceramics. Doing so requires a high temperature fiber, probably a fiber coating or surface treatment, to promote the desired weak interfacial bonding, and also requires a process that infiltrates and consolidates the matrix. Composites have the advantage of being resistant to crack growth and failure. Although current fibers for such materials do not yet have the completely desirable high temperature, oxidation resistance, and thermal expansion properties, there is progress being made in their formation ${ }^{19}$. Other options are to use carbon fibers and treat them to grade the thermal expansion and improve the oxidation resistance. Some preliminary work on these approaches and in forming composites using matrix materials described above is ongoing at Ames.

Modeling and computation are powerful tools for designing or refining materials and microstructures to tailor properties. There are efforts at Ames to model UHTCs at the atomic, molecular, and microscopic level.

\section{Conclusions}

Studies on monolithic UHTCs in the HfB2 family are useful as a means of demonstrating approaches to improving the critical properties of UHTCs. Approaches to improving fracture toughness through grain size reduction and grain shape control have been shown, as have approaches to improving oxidation resistance, again through grain size control and the addition of additives. It is possible to consider design approaches that can use monolithic materials until reliable approaches to making UHTC composites are developed. The monolithic materials and microstructural control demonstrated in this work will be critical to forming a composite material with tailorable material properties. The improvements in properties shown above demonstrates the usefulness of these materials for applications such as sharp leading edges and indicates the progress that can be made by compositional, processing, and microstructural control. Further progress aided by computation is expected, and the development of composite materials is underway.

\section{References}

\footnotetext{
${ }^{1}$ McHale, Anna E., "Phase Equilibrium Diagrams — Phase Diagrams for Ceramists," National Institute of Standards and Technology, Vol. X, The American Ceramic Society, 1994, pp.131, 145.

${ }^{2}$ Kontinos D., Gee K. and Prabhu, D. AIAA 2001-2886 35th AIAA Thermophysics Conference, 11-14 June 2001.

${ }^{3}$ Courtright, E. L., Graham, H. C., Katz, A. P. and Kerans, R. J. "Ultra High Temperature Assessment Study - Ceramic Matrix Composites," AFWAL-TR-91-4061, Wright Patterson Air Force Base, Ohio, 1992.

${ }^{4}$ Cutler, R. A. "Engineering Properties of Borides," ASTM Engineered Materials Handbook, Vol. 4, "Ceramics and Glasses," Schneider, S. J., Technical Chairman, 1991, p. 787-803.

${ }^{5}$ Guillermet, A. F. and Grimvall, G. "Phase Stability Properties of Transition Metal Diborides," Am. Inst. Phy. Conf. Proc., [231] 1991, 423-431.

${ }^{6}$ Kaufman, L. and Clougherty, E. V. "Investigation of Boride Compounds for Very High Temperature Applications," RTDTRD-N63-4096, Part III, ManLabs Inc., Cambridge, MA, March 1966.

${ }^{7}$ Clougherty, E. V, Kalish, D. and Peters, E. T. "Research and Development of Refractory Oxidaton Resistant Diborides," AFML-TR-68-190, ManLabs Inc., Cambridge, MA, (1968).

${ }^{8}$ Woo, S. K., Kim, C. H. and Kang, E. S. "Fabrication and Microstructural Evaluation of ZrB2/ZrC/Zr Composites by Liquid Infiltration," J. Mat. Sci. [2] 1994, pp. 5309-5315.

${ }^{9}$ Zhang, G., Deng, Z., Kondo, N., Yang, J. and Ohji, T. "Reactive Hot Pressing of ZrB2-Sic Composites," J. Am. Ceram. Soc. [83] 2002, pp. 2330-2332.

${ }^{10}$ Levine, S., Opila, E., Halbig, M., Kiser, J., Singh, M. and Salem, J., "Evaluation of Ultra-High Temperature Ceramics for Aeropropulsion Use," J. Europ. Ceram. Soc. [22] 2002, pp. 2757-2767.

${ }^{11}$ Bargeron, C. B., Benson, R. C., Newman, R. W., Jette, A. N. and Phillips, T. E. "Oxidation Mechanisms of Hafnium Carbide and Hafnium Diboride in the Temperature Range 1400-2100 ${ }^{\circ}$ C," Johns Hopkins APL Technical Digest, [14] 1993, 29-35.

${ }^{12}$ Monteverde, F. and Bellosi, A. "Effect of the Addition of Silicon Nitride on Sintering Behavior and Microstructure of Zirconium Diboride," Scripta Materialia, [46] 2002, pp. 223-228.

${ }^{13}$ Monteverde, F., Bellosi, A and Guicciardi, S. "Processing and Properties of Zirconium Diboride-Based Composites," J. Europ. Ceram. Soc., [22] 2002, pp. 279-288.
} 
${ }^{14}$ Shimada, S. "A Thermoanalytical Study on the Oxidation of $\mathrm{ZrC}$ and HfC Powders with Formation of Carbon," Solid State Ionics, [149] 2002, pp. 319-326.

${ }^{15}$ Kolodziej, P., Salute, J. and Keese, D. L. "First Flight Demonstration of a Sharp Ultra-High Temperature Ceramic Nosetip,” NASA TM-112215, 1997.

16 Johnson, Sylvia M. et al., "UHTC Development at NASA: Challenges and Successes, NASA Ames Research Center" Ultra-High Temperature Ceramics: Materials for Extreme Environment Applications, conference, 2008.

${ }^{17}$ Kingery, W.D., Bowen, H.K., Uhlmann, D.R., Introduction to Ceramics, $2^{\text {nd }}$ ed., John Wiley \& Sons, New York, 1976 , p.795.

${ }^{18}$ M. Schüßler, M. Auweter-Kurtz, G. Herdrich, S. Lein, "Surface characterization of metallic and ceramic TPS-materials for reusable space vehicles" Acta Astronautica, Volume 65, Issues 5-6, 2009, pp. 676-686.

${ }^{19}$ SBIR Phase II Contract: NNX08CA07C Firm: MATECH Advanced Materials, ARC. 


\section{Recent Developments in Ultra High Temperature Ceramics at NASA Ames}

16th AIAA/DLR/DGLR International Space Planes \& Hypersonic Systems \& Technologies Conference 19-22 October 2009 Bremen, Germany

Sylvia M. Johnson, Matt Gasch, John Lawson NASA Ames Research Center Mike Gusman, Mairead Stackpoole ELORET Corporation 


\section{Outline}

- Background and objectives

- Research at NASA Ames

- Controlling microstructure and composition

- Experimental effort

- Computational effort

- Summary \& plans for the future 


\section{Sharp Leading Edge Technology}

- Sharp leading edge technology

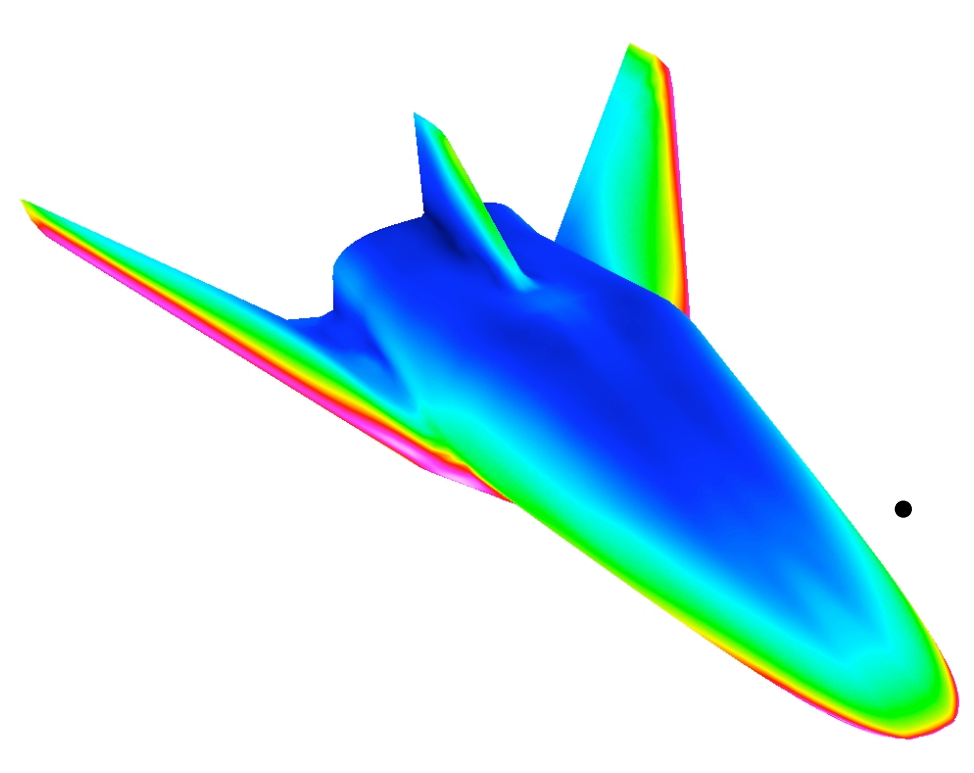

- Enhances vehicle performance

- Leads to improvements in safety

- Increased vehicle cross range

- Greater launch window with safe abort to ground

- Sharp leading edges place significantly higher temperature requirements on the materials:

- Current shuttle RCC leading edge materials: $\mathrm{T} \sim 1650{ }^{\circ} \mathrm{C}$

- Sharp leading edged vehicles will require: $\mathrm{T}>2000^{\circ} \mathrm{C}$

Ultra High Temperature Ceramics are candidates for use in sharp leading edge applications. 


\section{Fundamental Aeronautics Program (FAP)}

Long-term, multidisciplinary investment in critical research of core areas in aeronautics technology.

- Evaluate new concepts and technology.

- Accelerate new technology applications.

- Research tied to tool development, not specific vehicle / mission. 


\section{RALV: Reusable Airbreathing Launch Vehicles}

Hypersonic materials and structures focus:

- Materials and structures discipline - advance fundamental understanding of key hypersonic high temperature materials from atomic, constituent, test coupon, $\&$ structural application to reduce weight \& increase reliability.

- Integrated analysis methods

- Thermal protection systems

- Advanced structural concepts

- Propulsion materials/structures 


\section{UHTC Material Property Considerations}

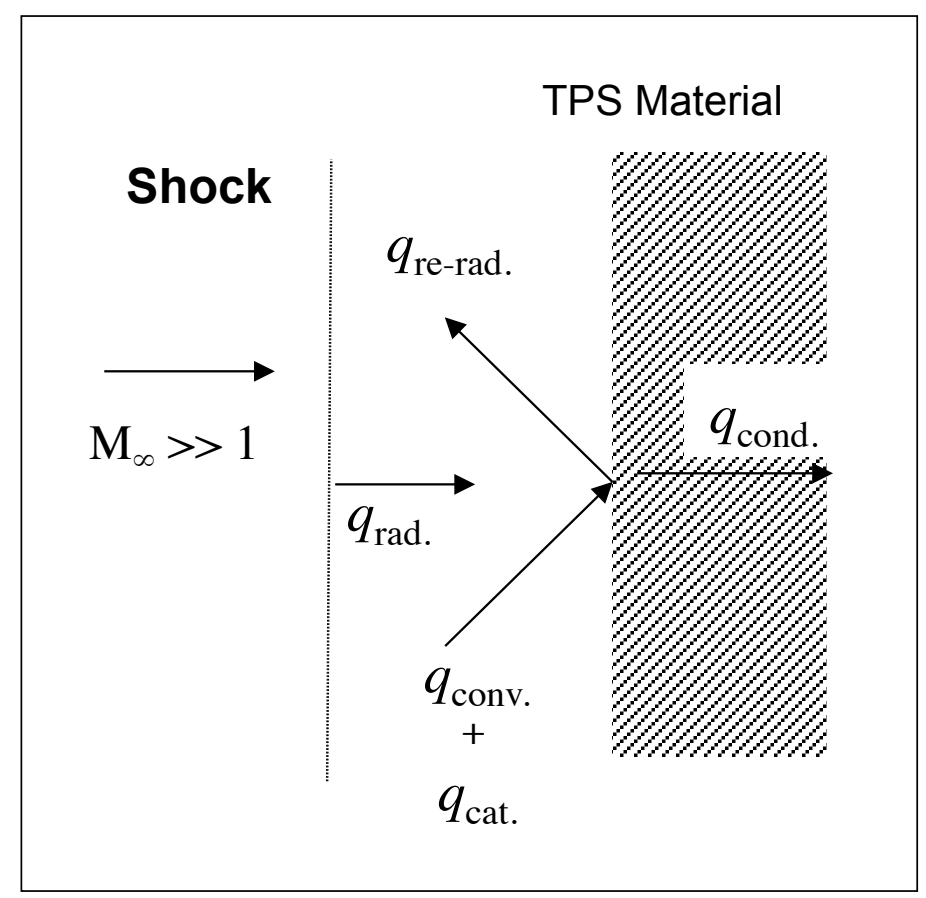

$q_{\text {re-rad. }}=\varepsilon_{w} \sigma T_{w}^{4}$, where $\varepsilon_{w}=$ emissivity
- Emittance determines amount of reradiated energy.

- Emittance should be as high as possible

- Surface oxidation can reduce emittance

- Thermal diffusivity determines amount of energy conducted within the material.

- High thermal conductivity is desirable in sharp leading edge applications.

- Enhances vehicle performance

- Increases thermal shock resistance

- Catalycity determines amount of chemical energy released near the surface due to recombination of dissociated species.

- Surface catalycity should be low

- Catalycity estimated from temperature measurements during arcjet experiment

- If facility conditions are known and material properties (such as emittance and thermal diffusivity) are known, then the heating from catalycity can be estimated. 


\section{UHTCs for Sharp Leading Edges}

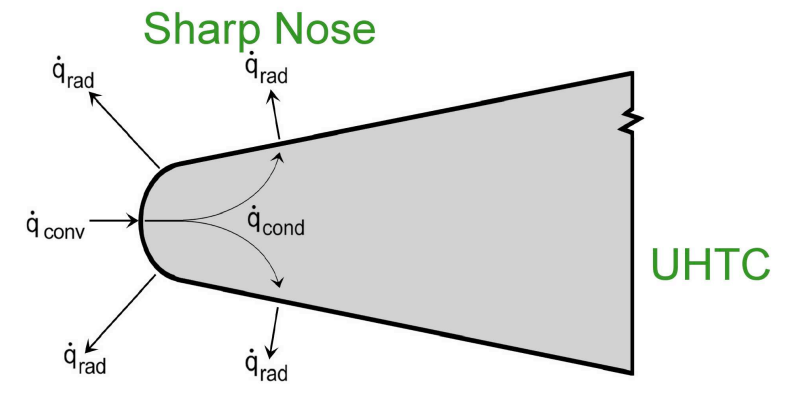

High Thermal Conductivity

$$
\dot{q}_{\text {conv }}=\dot{q}_{\text {rad }}+\dot{q}_{\text {cond }}
$$

Dean Kontinos, Ken Gee, and Dinesh Prabhu. "Temperature Constraints at the Sharp Leading Edge of a Crew Transfer Vehicle." AIAA 2001-2886 35th AIAA

Thermophysics Conference, 11-14 June 2001, Anaheim CA
- Energy is managed differently at a sharp leading edge:

- Insulators store energy until it can be eliminated in the same way that it entered.

- UHTCs conduct energy through the material and reradiate it through cooler surfaces.

- Properties that sharp leading edges require of UHTCs:

- High thermal conductivity (directional)

- High fracture toughness/ mechanical strength/hardness

- Oxidation resistance (in reentry conditions) 


\section{Background on UHTC Development at AMES}

- $\mathrm{Hf}$ and $\mathrm{ZrB}_{2}$ materials were investigated in the early 1950 s for use as nuclear reactor material.

- Extensive work in the 1960s and 1970s by ManLabs for the Air Force showed potential for $\mathrm{HfB}_{2}$ and $\mathrm{ZrB}_{2}$ for use as nosecones and leading edge materials (Clougherty, Kaufman, Kalish, Hill, Peters, Rhodes et al.)

- During the 1990s, NASA Ames investigated $\mathrm{HfB}_{2} / \mathrm{SiC}, \mathrm{ZrB}_{2} / \mathrm{SiC}$ ceramics for sharp leading edges.

- Ballistic flight experiments: Ames teamed with Sandia National Laboratories New Mexico, Air Force Space Command, and TRW.

- SHARP*-B1 (1997) UHTC reentry nosetip

- SHARP-B2 (2000) UHTC reentry strake assembly

- Space Launch Initiative (SLI) (Lockheed-Martin work)

- Further development under NASA's FAP (ended 9/2009))

- Substantial research is being performed in the U.S., Europe, and Asia

*Slender Hypervelocity Aerothermodynamic Research Probes (SHARP) 


\section{Flight Hardware}

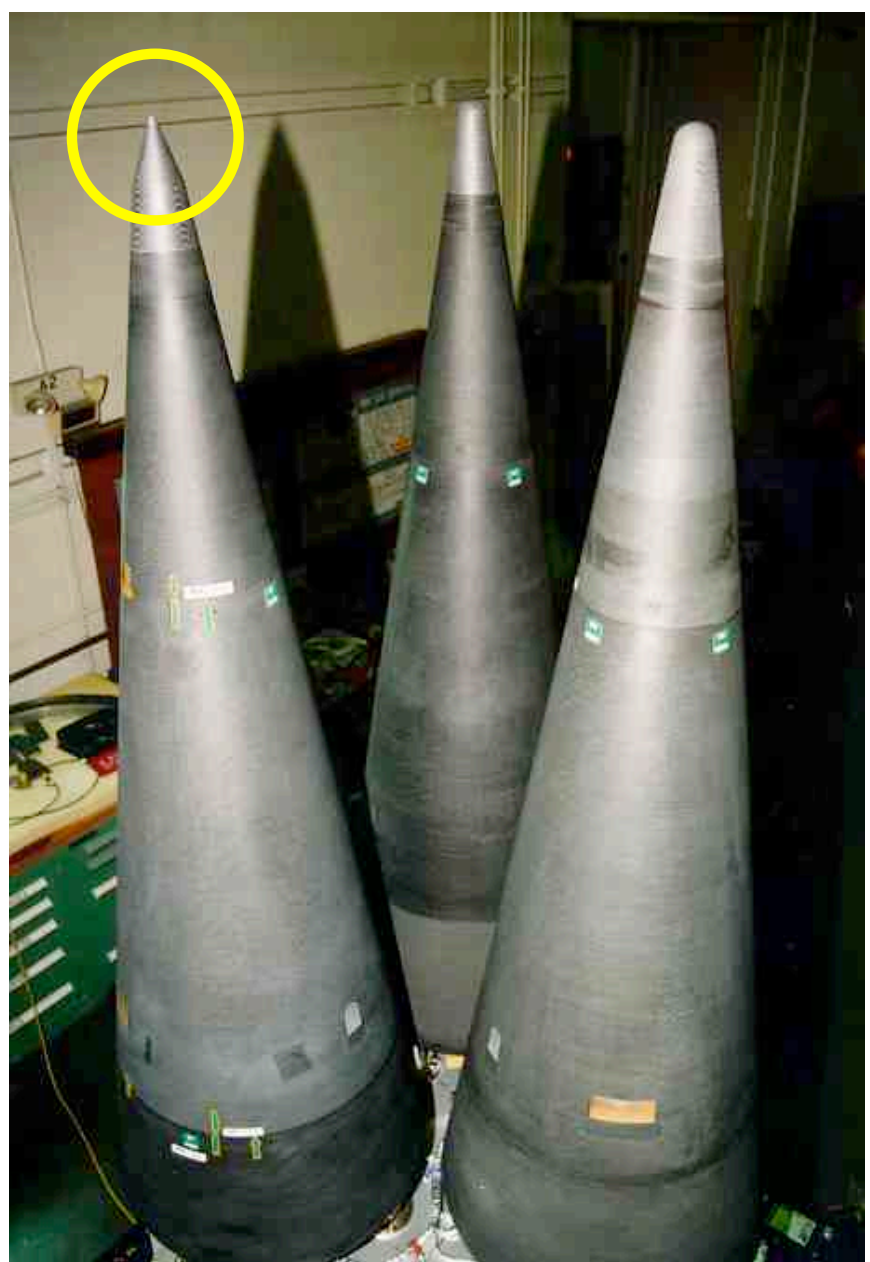

SHARP-B1 May 21, 1997

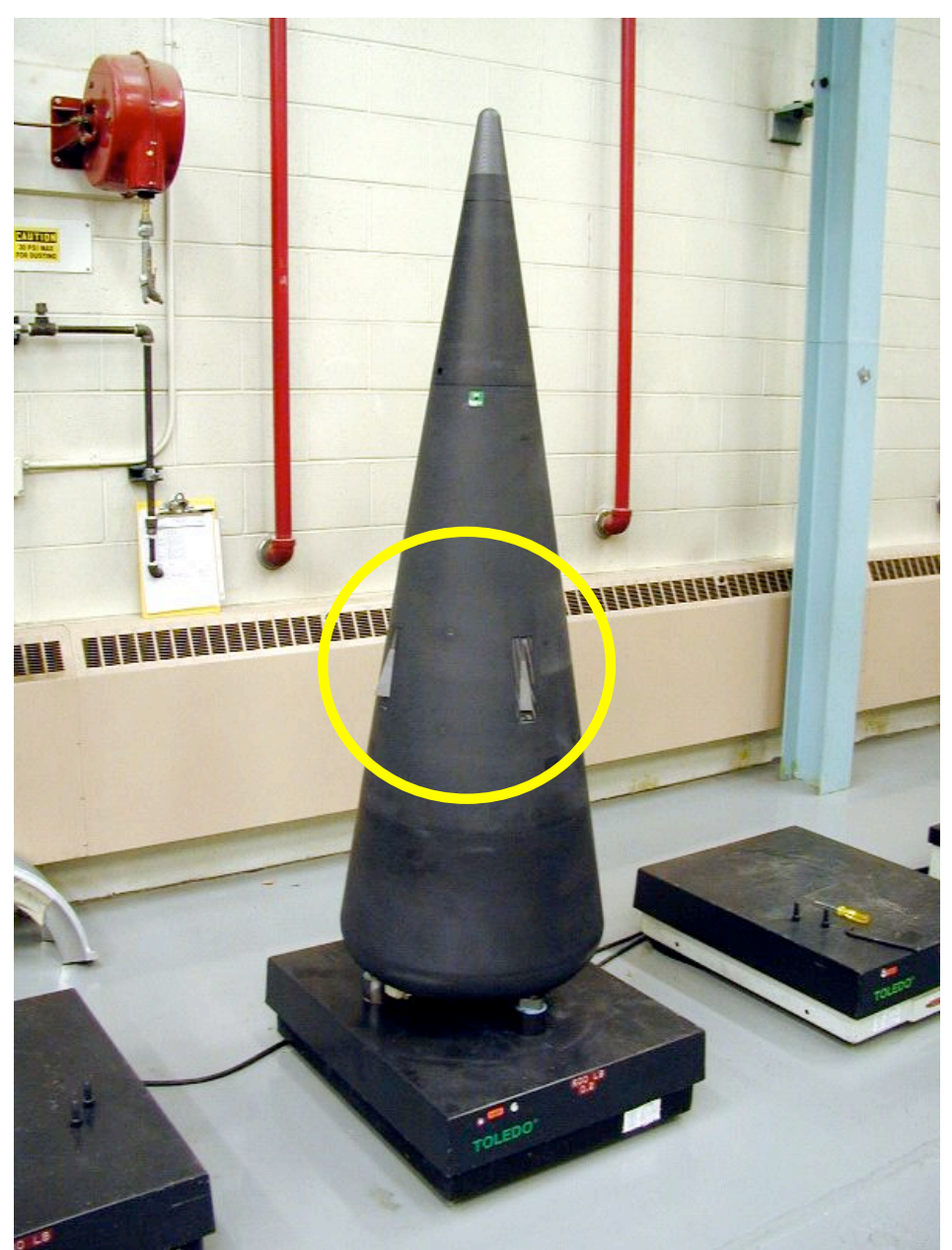

SHARP-B2 Sept. 28, 2000 


\section{SHARP-B1 (May 1997)}

- Modified MARK12A reentry vehicle, with Carbon/Carbon nose cap replaced with one containing $\mathrm{HfB}_{2} / \mathrm{SiC}$ UHTC insert with small "sharp" nose radius.

- Objectives:

- Demonstrate non-ablating performance of the 3D UHTC "sharp" nosetip exposed to a ballistic aerothermal environment.

- Correlate ground based sensors with flight sensors to characterize the material performance.

- Flight data indicated materials were promising, but material was not recovered. 


\section{SHARP-B2 Flight Experiment}

(September 2000)

Objective: to determine the performance of sharp UHTC components in a flight reentry environment.

- Four UHTC strakes were attached to a USAF Mk12A reentry vehicle (RV) deployed from a Minuteman III launch vehicle.

- The Mk12A was a ballistic sphere-cone RV with a carbon-carbon (C/C) nose tip and a carbon-phenolic heat shield.

- The strakes were exposed to the reentry environment and then retracted, in pairs, at two different altitudes.

The two altitudes for retraction corresponded to the points in the trajectory when the UHTC materials were predicted to reach their multi-use and single-use temperature limits; these were at $47.9 \mathrm{~km}$ (157 kft) and $43.3 \mathrm{~km}$ (142 kft), respectively.

- After the last pair of strakes retracted, a parachute slowed the vehicle for a "soft water" impact in the southern Pacific Ocean. The vehicle and strakes were recovered, which allowed additional direct inspection of the components. 


\section{SHARP-B2 Segmented Strake}

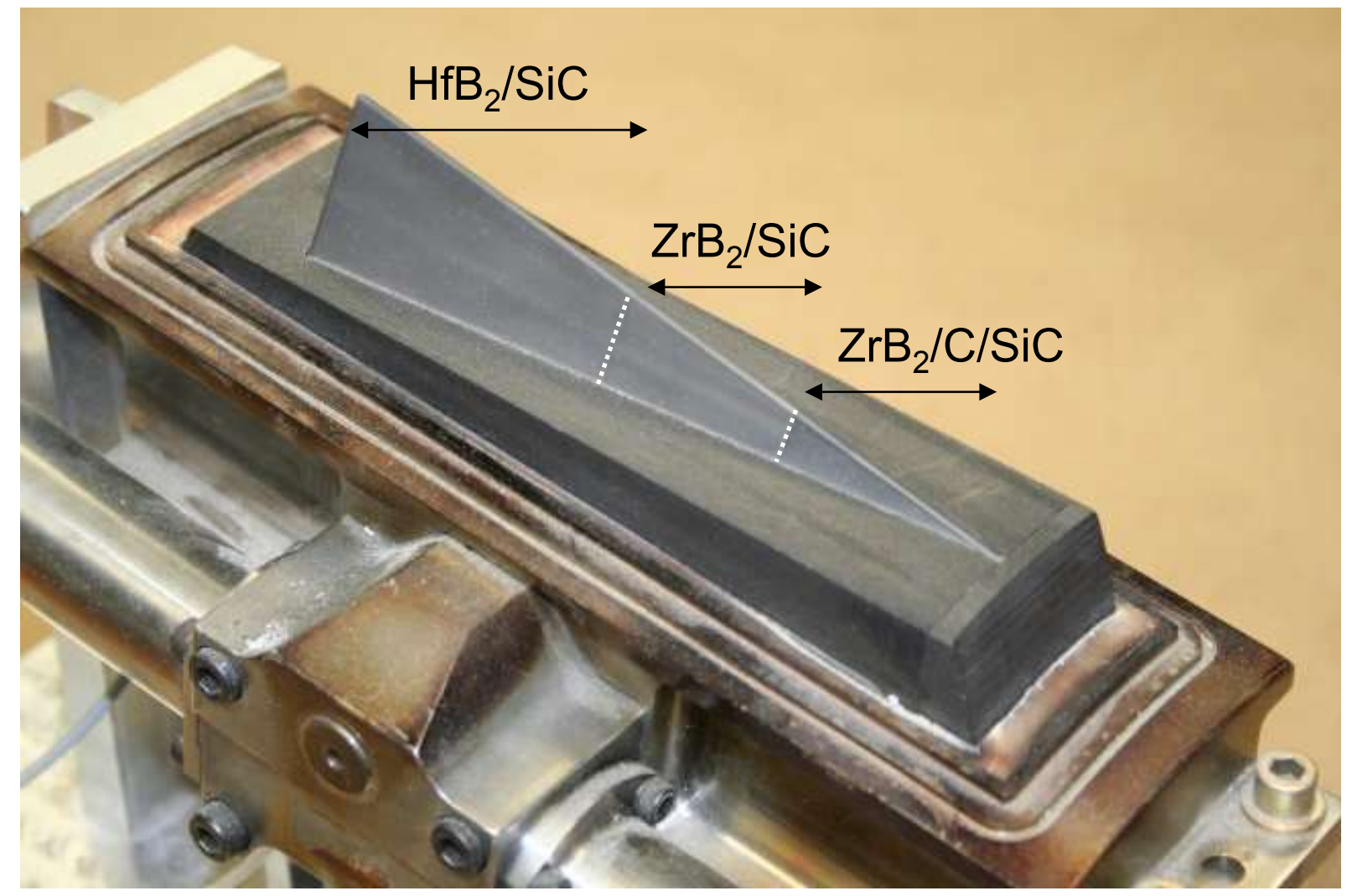

The strakes were composed of three sections, each having a different UHTC composition. 


\section{SHARP-B2}

- Flight test designed to evaluate three different compositions of UHTCs in strake (fin) configuration exposed to ballistic reentry environment.

- Strakes exposed as vehicle reentered atmosphere and then retracted into protective housing.

- Material recovered - significant materials processing issues.

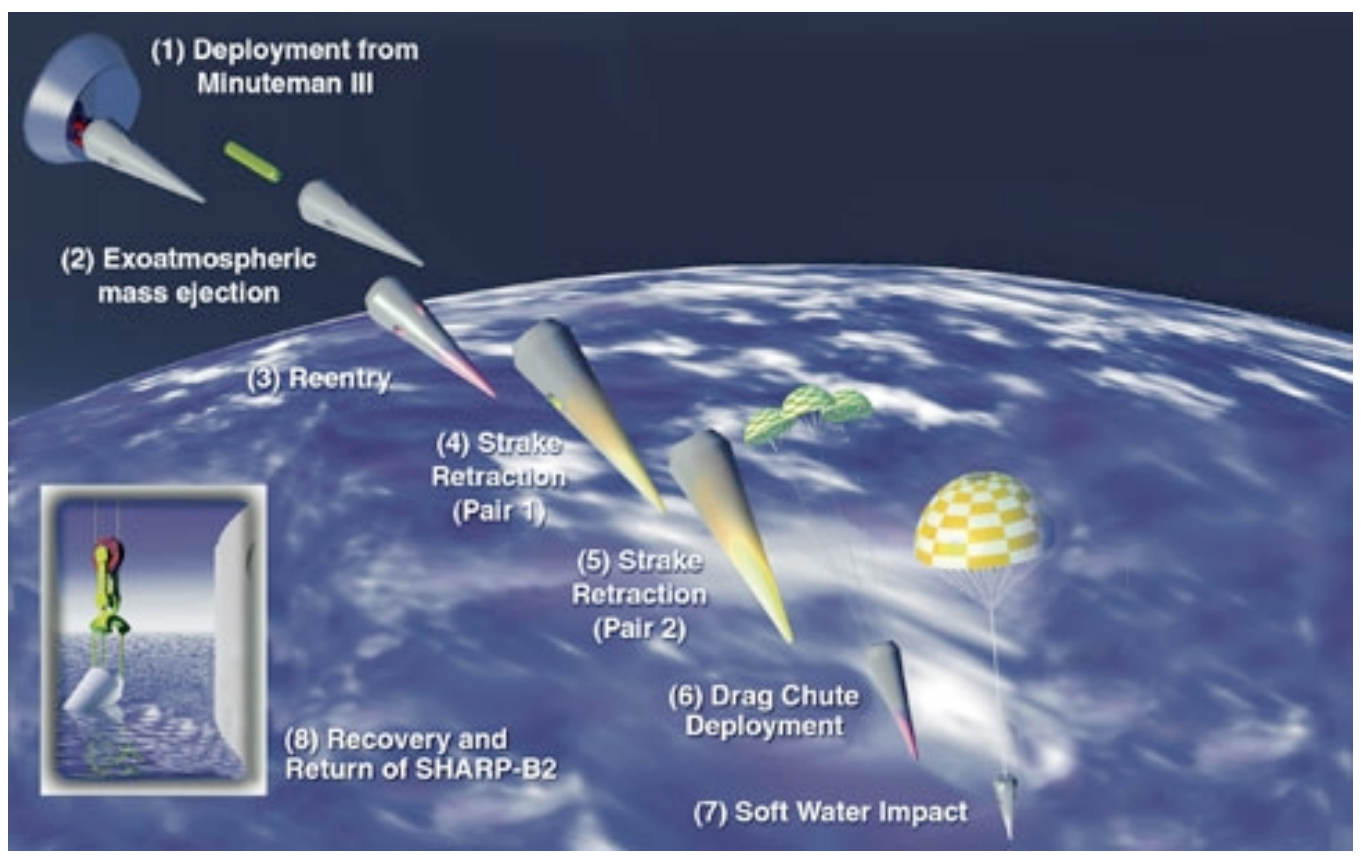




\section{UHTC Research at NASA Ames}

- Controlling microstructure and composition to improve properties

- Strength

- Fracture toughness

- Thermal conductivity

- Oxidation resistance in re-entry

- Focus has been on monolithic materials and in situ composites

- Goal is to incorporate our research into both monolithic and composite materials 


\section{Controlling Microstructure \& Composition}

- Control grain size

- Additives (Ir additions)

- Processing by field-assisted sintering (FAS)

- Control grain shape

- Addition of preceramic polymers

- Particle coatings (Fluidized Bed CVD)

- Control purity (grain boundaries)

- Addition of preceramic polymers

- Processing (FB CVD)

- Self-propagating reactions

- Control oxide formation

- Increase oxide stability / emissivity (additives)

- Reduce amount of SiC 


\section{Controlling Grain Size}

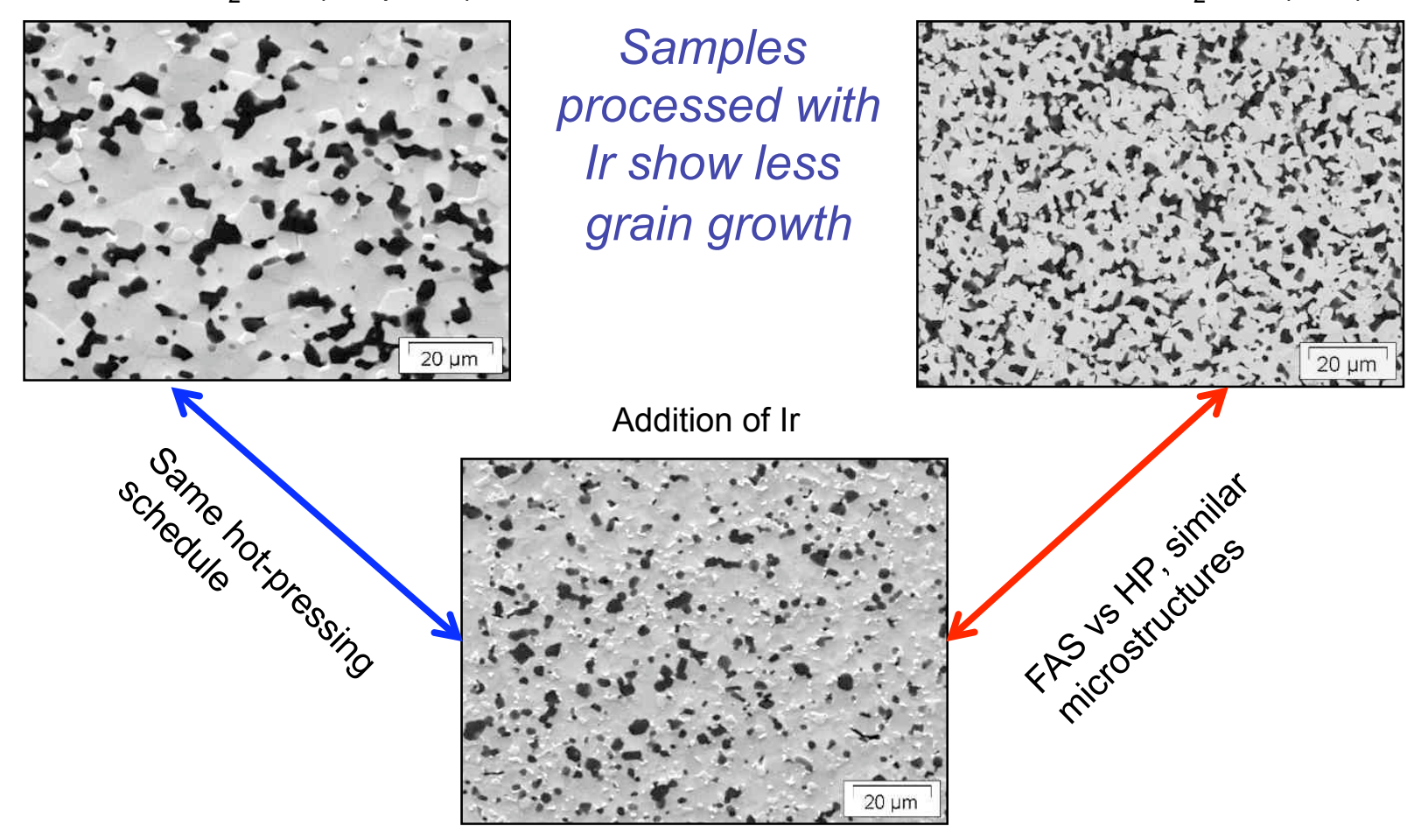

$\mathrm{HfB}_{2}-20 \% \mathrm{SiC}-1 \%$ Ir (hot press)

- Additives (Ir additions) - improve microstructures of hot-pressed materials to match that of FAS materials (very refined)

- Processing (FAS) - refined microstructure 


\section{Effect of Processing on Microstructure and Properties}

$\mathrm{HfB}_{2} / 20 \mathrm{v} \% \mathrm{SiC}$ Hot Pressed (long process)

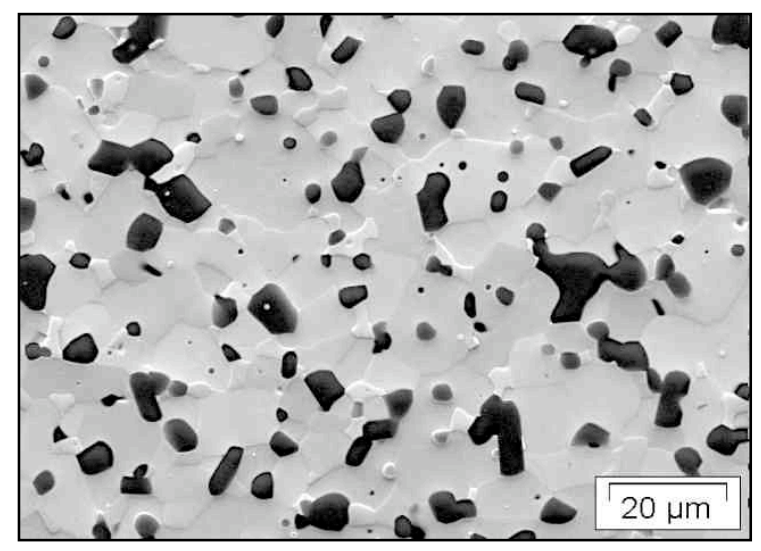

Hardness and fracture toughness increase with:

- Processing - shorter times

-Additional phases - Ir \& $\mathrm{TaSi}_{2}$
$\mathrm{HfB}_{2} / 20 \mathrm{v} \% \mathrm{SiC}$ Hot Pressed (short process)

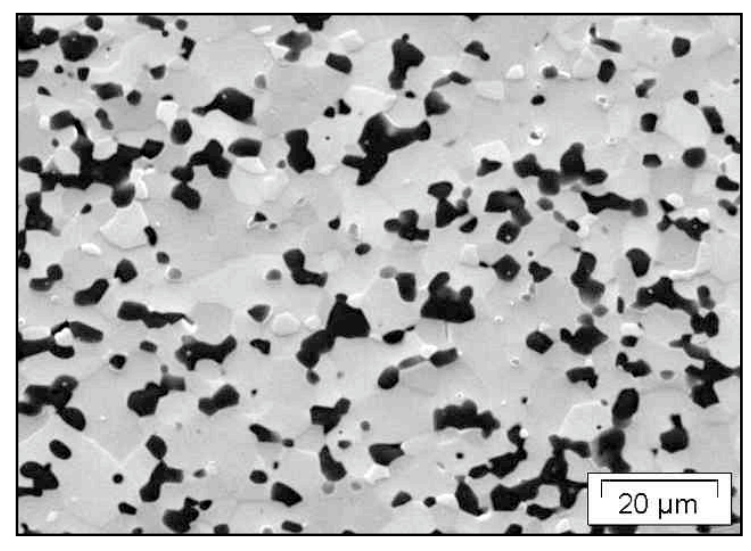

$\mathrm{HfB}_{2} / 20 \mathrm{v} \% \mathrm{SiC}$

Field Assisted Sintered

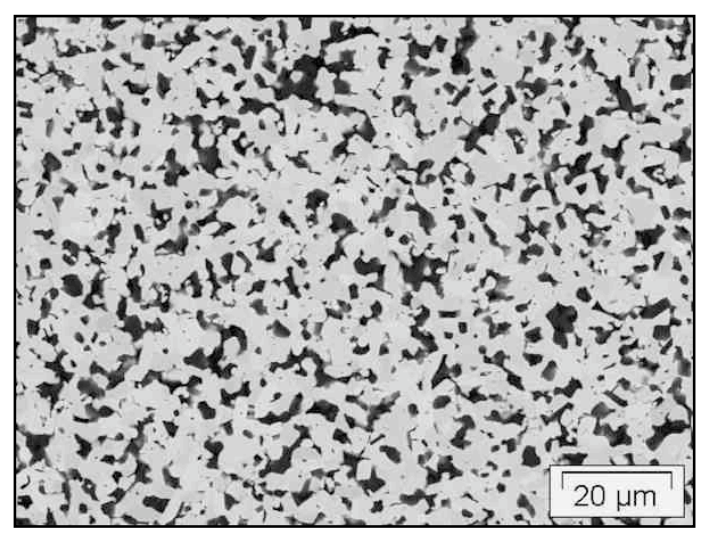

\begin{tabular}{|ccc|}
\hline Material & $\begin{array}{c}\text { Hardness } \\
\mathrm{GPa}\end{array}$ & $\begin{array}{c}\text { Toughness } \\
\mathrm{MPa}^{*} \mathrm{~m}^{1 / 2}\end{array}$ \\
\hline $\begin{array}{c}\text { Baseline UHTC } \\
\text { (long process) } \\
\text { UHTC }+ \text { Ir }\end{array}$ & $16.5 \pm 0.2$ & $4.3 \pm 0.6$ \\
\hline
\end{tabular}




\section{Controlling Grain Shape}

- Addition of preceramic polymers as SiC source

- Growing acicular SiC grains

- Potentially improving:

- Mechanical properties with reduced amount of SiC — changes crack path and improves toughness

- Oxidation behavior

- Particle coatings (Fluidized Bed CVD)

- Grow acicular SiC grains

- Maintain clean grain boundaries

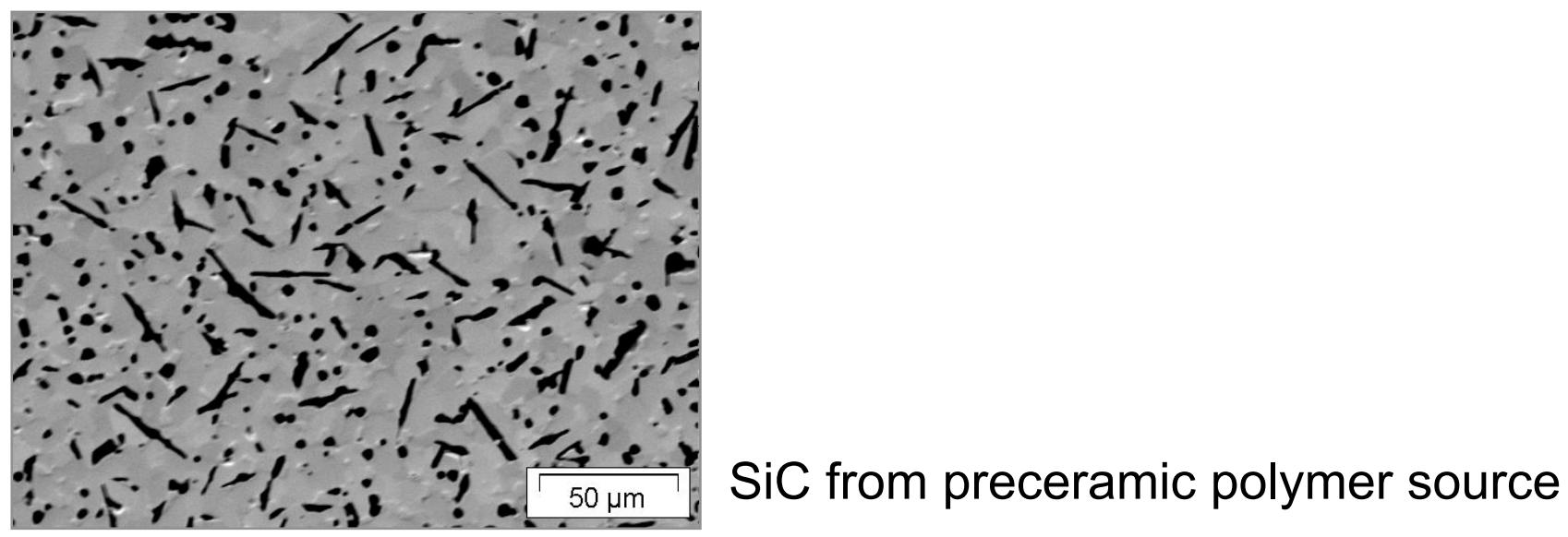




\section{Additives as Preceramic Polymer}

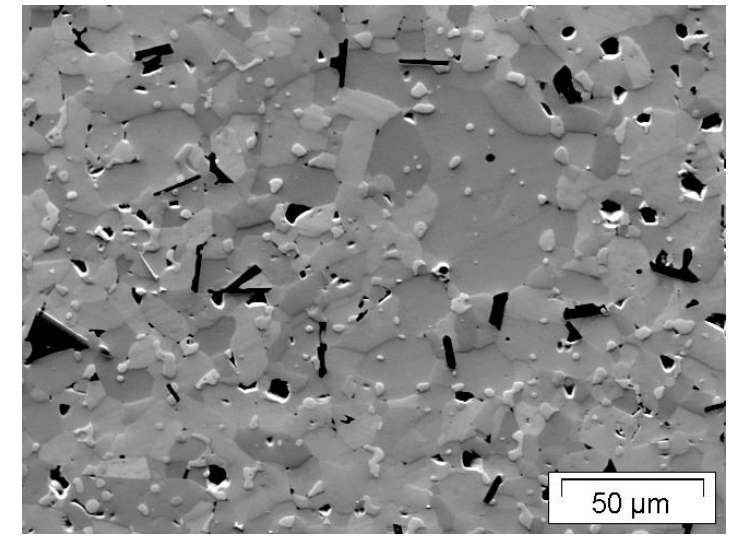

$5 \% * \mathrm{SiC}$

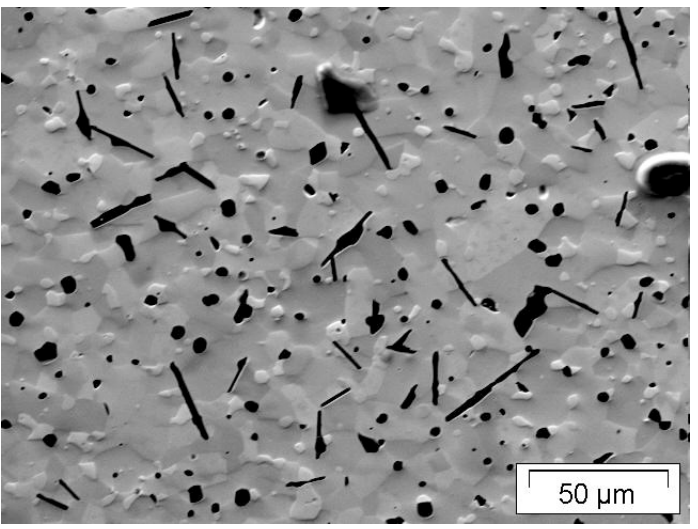

$10 \%$ * $\mathrm{SiC}$

Rod diameter $\sim 2 \mu \mathrm{m}$

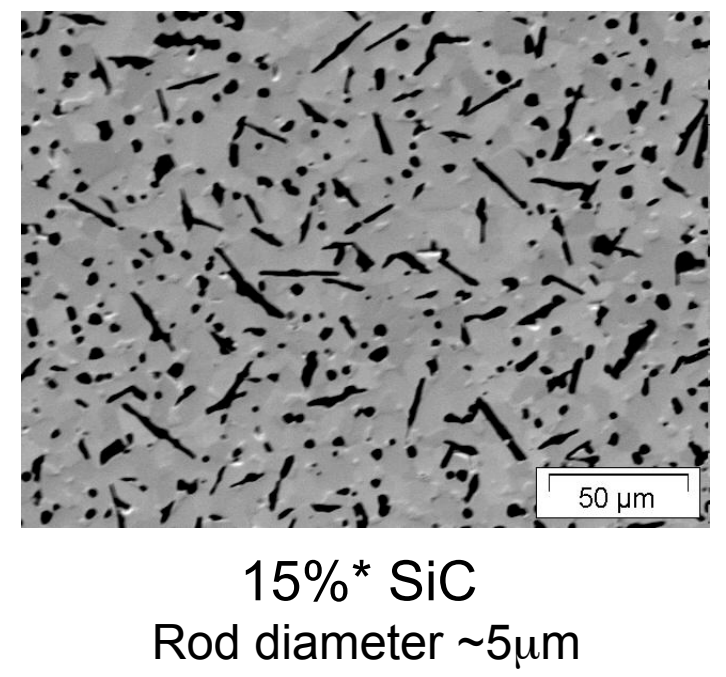

- Samples processed with 5 to $>20$ volume $\% \mathrm{SiC}$

- Can adjust volume of $\mathrm{SiC}$ in the UHTC without losing the high l/d architecture

- Amount of SiC affects number and thickness (but not length) of rods length constant $(\sim 20-30 \mu \mathrm{m})$

* Precursor added in amounts sufficient to yield nominal amounts of SiC 


\section{Acicular Grains from Preceramic Polymer Enhance Crack Deflection}

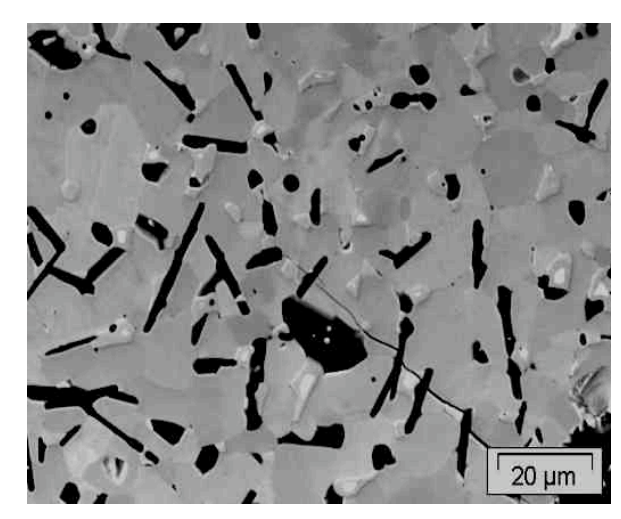

Evidence of crack growth along $\mathrm{HfB}_{2}-\mathrm{SiC}$ interface with possible $\mathrm{SiC}$ grain bridging
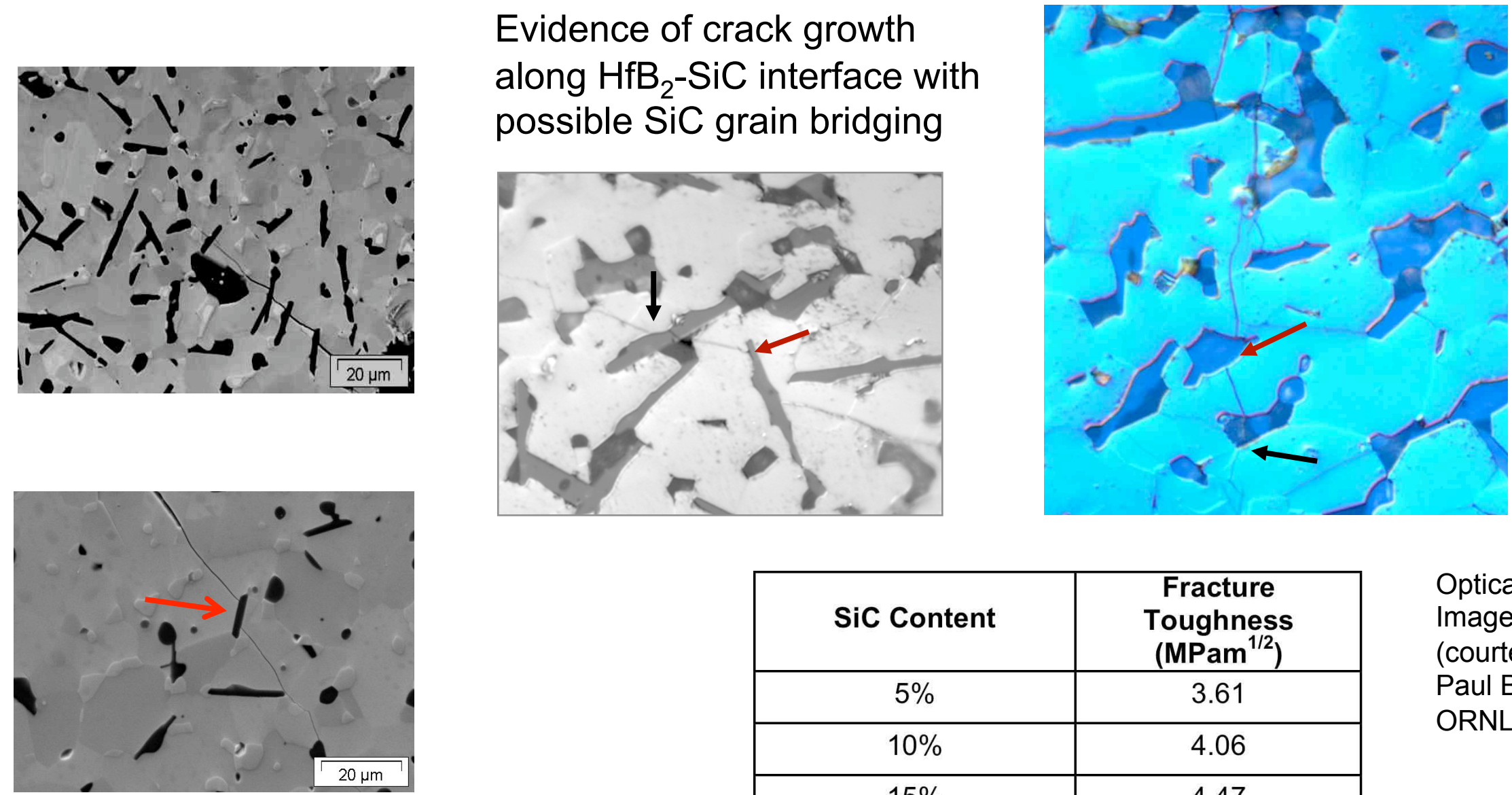

SEM Images

\begin{tabular}{|c|c|}
\hline SiC Content & $\begin{array}{c}\text { Fracture } \\
\text { Toughness } \\
\text { (MPam }^{1 / 2} \text { ) }\end{array}$ \\
\hline $5 \%$ & 3.61 \\
\hline $10 \%$ & 4.06 \\
\hline $15 \%$ & 4.47 \\
\hline Baseline UHTC (20\%) & 4.33 \\
\hline
\end{tabular}

Optical Images (courtesy Paul Becher, ORNL)

High-aspect-ratio $\mathrm{SiC}$ increases toughness for a given $\mathrm{SiC}$ loading 


\section{Growth of SiC Rods}

Even in poorly processed and consolidated $\mathrm{HfB}_{2}$-SiC composites, $\mathrm{SiC}$ appears to bridge pores.

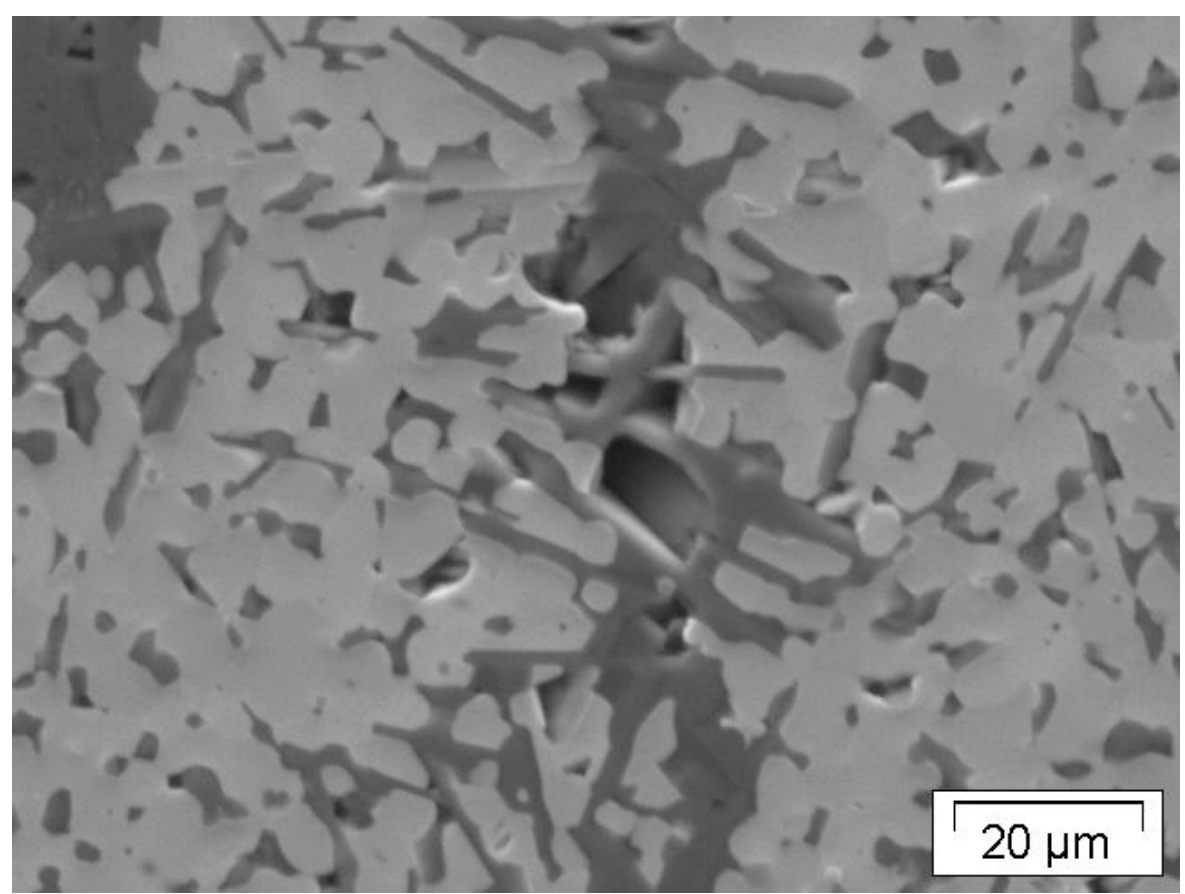




\section{Preceramic Polymer SiC \\ Source}

High SiC Loadings

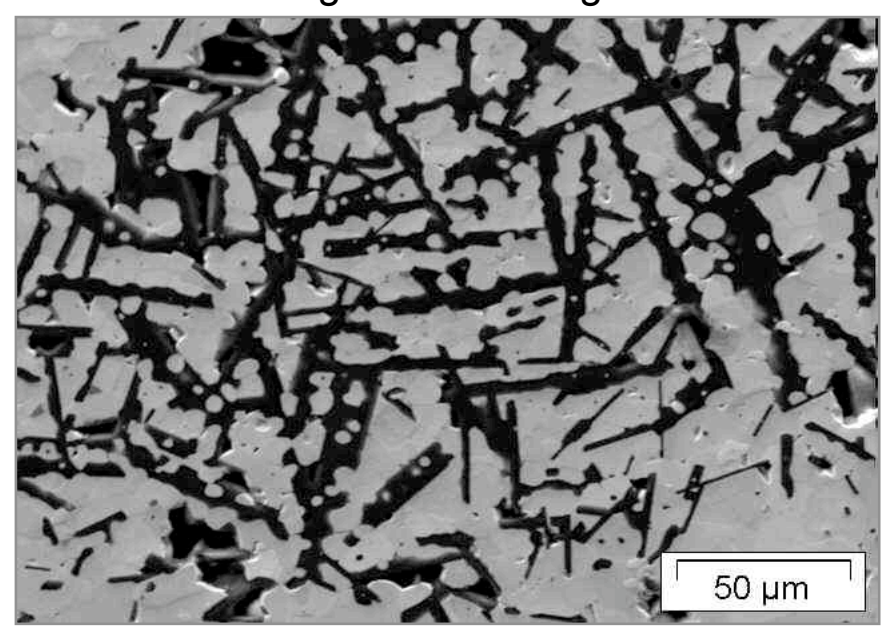

- High SiC loadings result in 3D interconnected network of SiC

- Majority of SiC coalesced and formed larger grains - some finer acicular SiC grains still evident

- High aspect ratio architecture of the $\mathrm{SiC}$ phase is preserved
Approach to grow high aspect phases demonstrated on borides and carbides

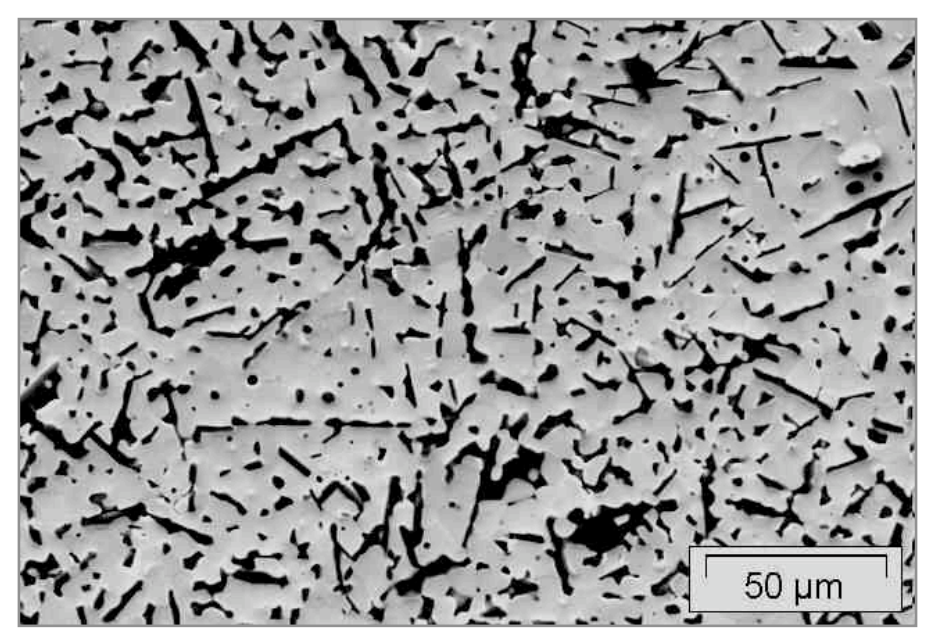

- $15 \% \mathrm{SiC}$ high-aspect-ratio phase in a $\mathrm{ZrB}_{2}$ matrix

- Also demonstrated in carbide systems 


\section{Reducing Oxide Formation}

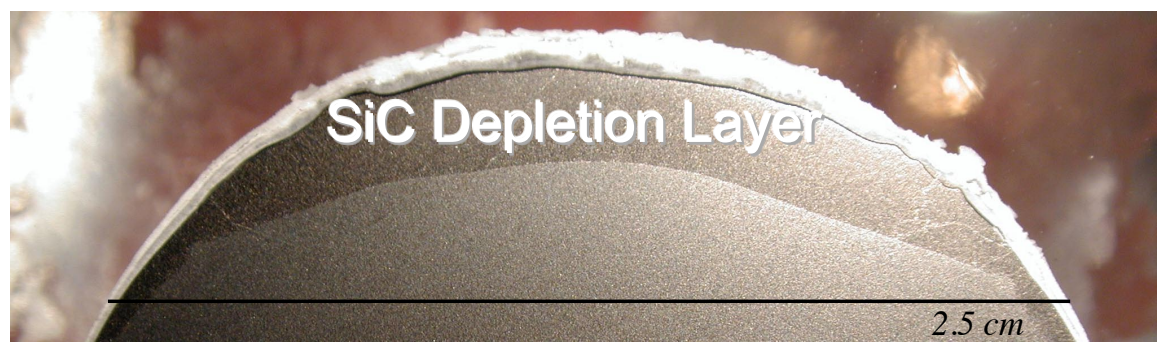

*Post-test arc jet nosecone model after a total of 80 minutes of exposure. Total exposure the sum of multiple 5- and 10-minute exposures.

- In baseline material:

- SiC depleted during arcjet testing

- Surface oxide is porous

- Potential solution: Reduce amount of $\mathrm{SiC}$ below the percolation threshold while maintaining mechanical performance

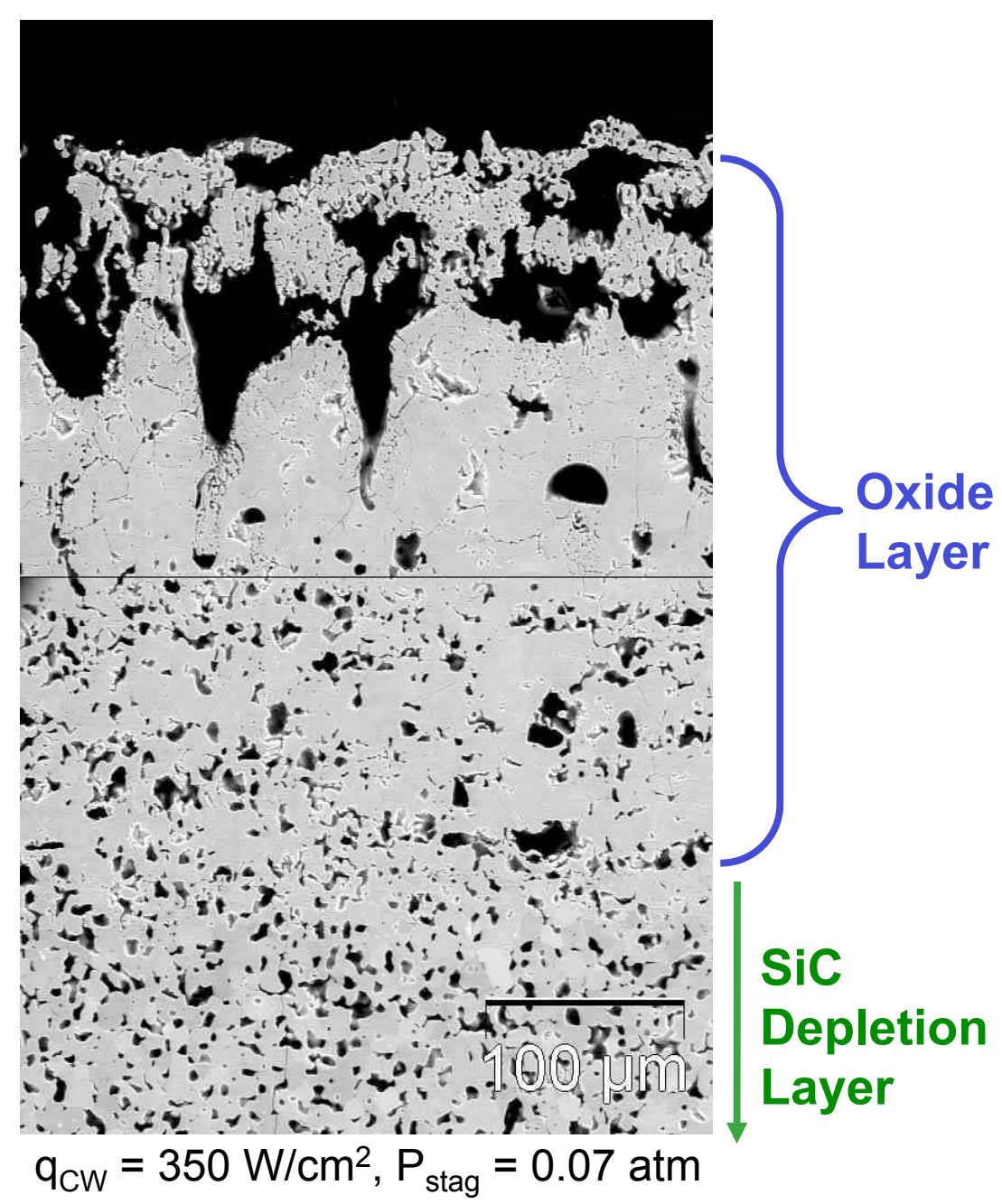




\section{Increasing Oxide Emissivity}

\section{$\mathrm{HfB}_{2}-\mathrm{SiC}$}

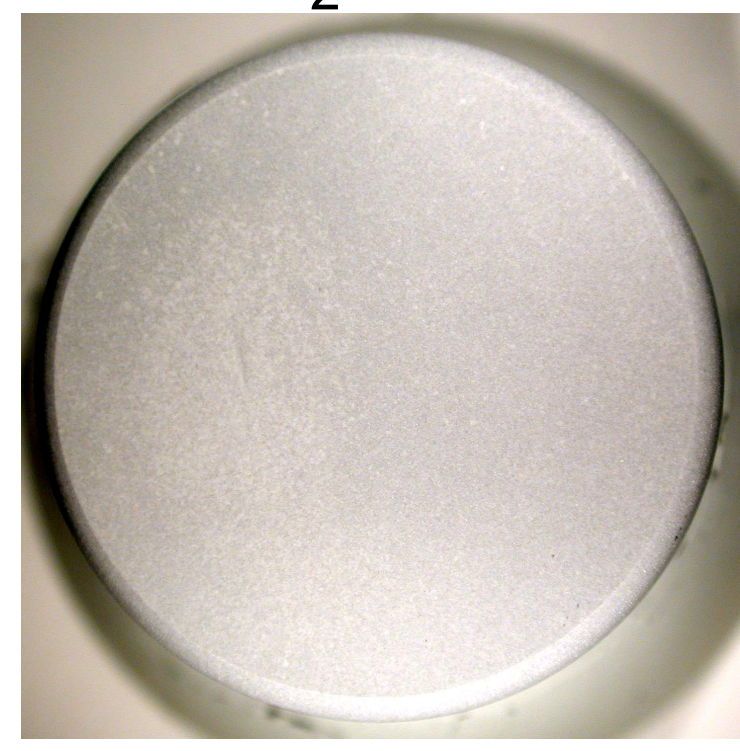

$\mathrm{HfB}_{2}-\mathrm{SiC}-\mathrm{TaSi}_{2}$

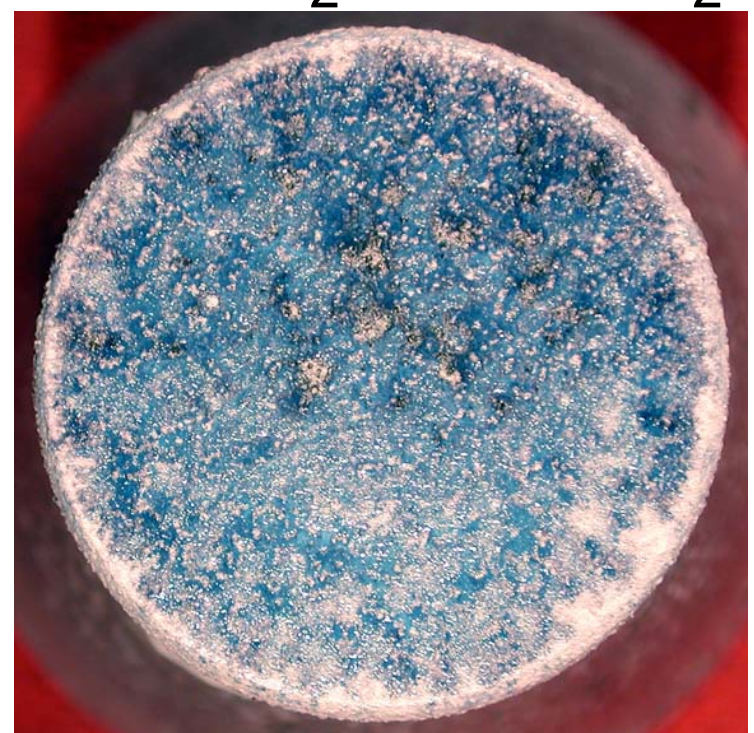

- Arcjet test: Performance of $\mathrm{HfB}_{2} / \mathrm{SiC} / \mathrm{TaSi}_{2}$ comparable to $\mathrm{HfB}_{2} / \mathrm{SiC}$ after testing for 5 minutes at $\mathrm{Q}_{\mathrm{cw}} \sim 300 \mathrm{~W} / \mathrm{cm}^{2}$

- $\mathrm{HfB}_{2} / \mathrm{SiC} / \mathrm{TaSi}_{2}$ clearly has a higher post-test emissivity than $\mathrm{HfB}_{2} / \mathrm{SiC}$ and demonstrated lower surface temperatures 


\section{Physical Characterization: Microstructure}
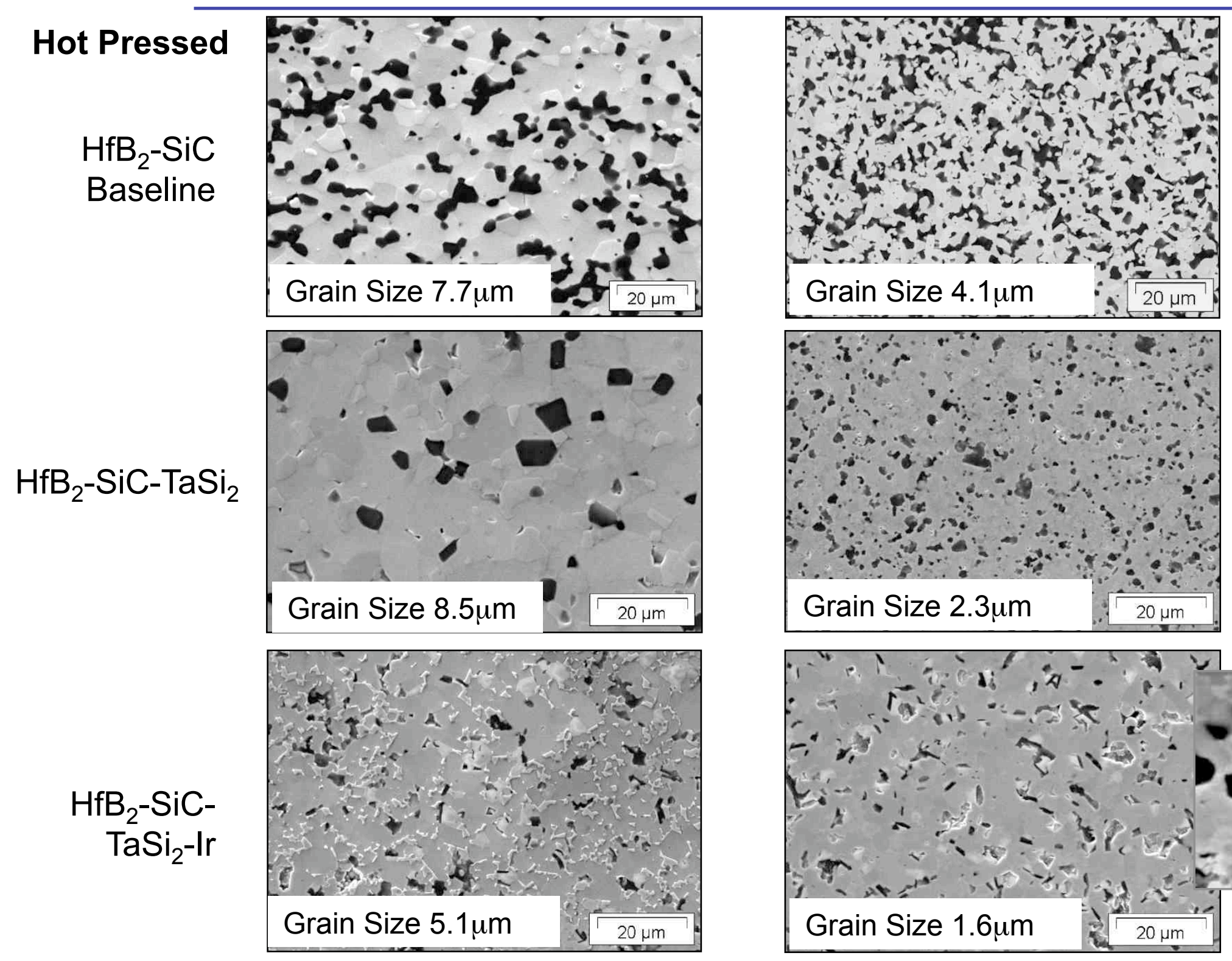

Field-Assist Sintered (FAS)

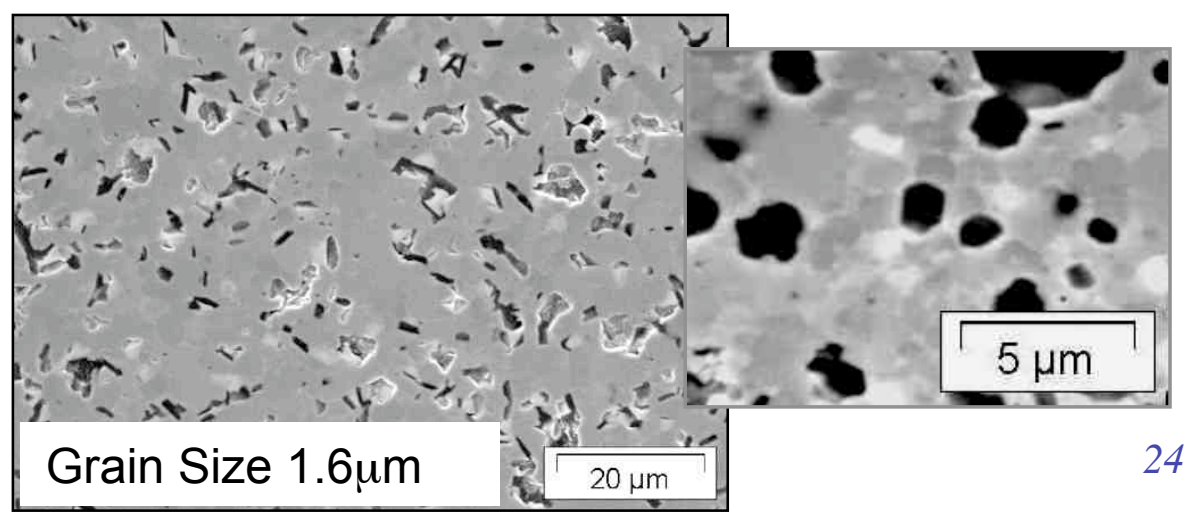




\section{Arcjet Characterization: Surface}
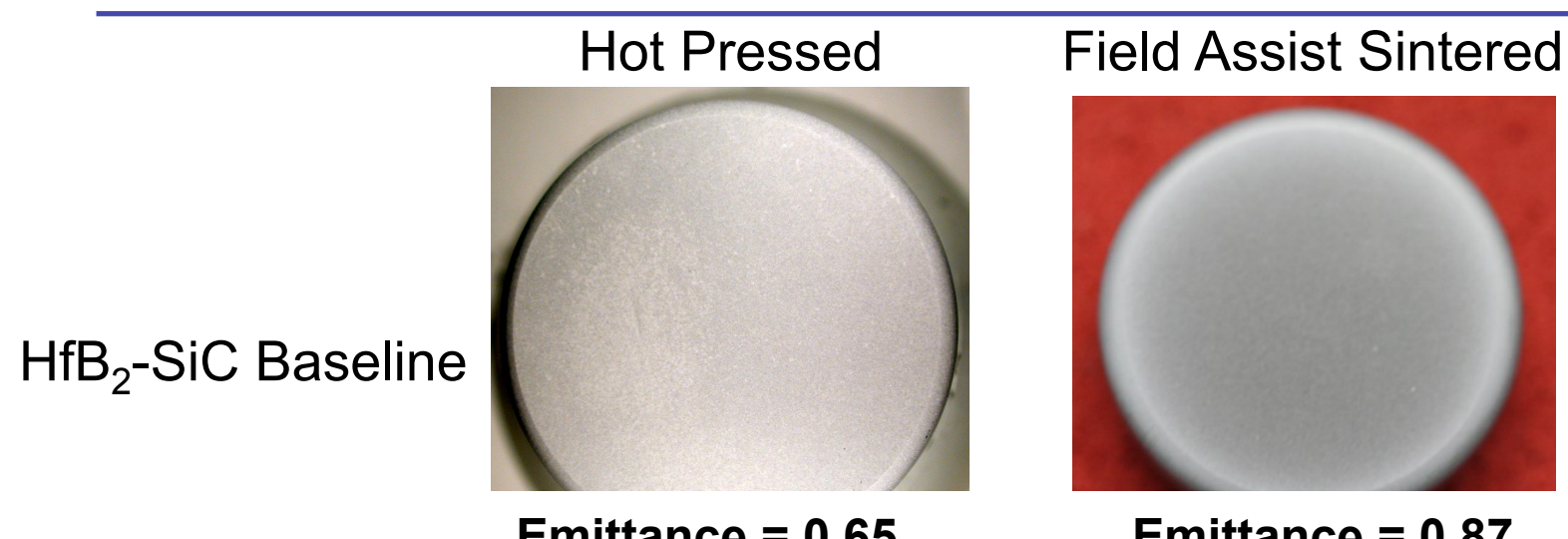

\section{Emittance $=0.65$}

\section{Emittance $=\mathbf{0 . 8 7}$}

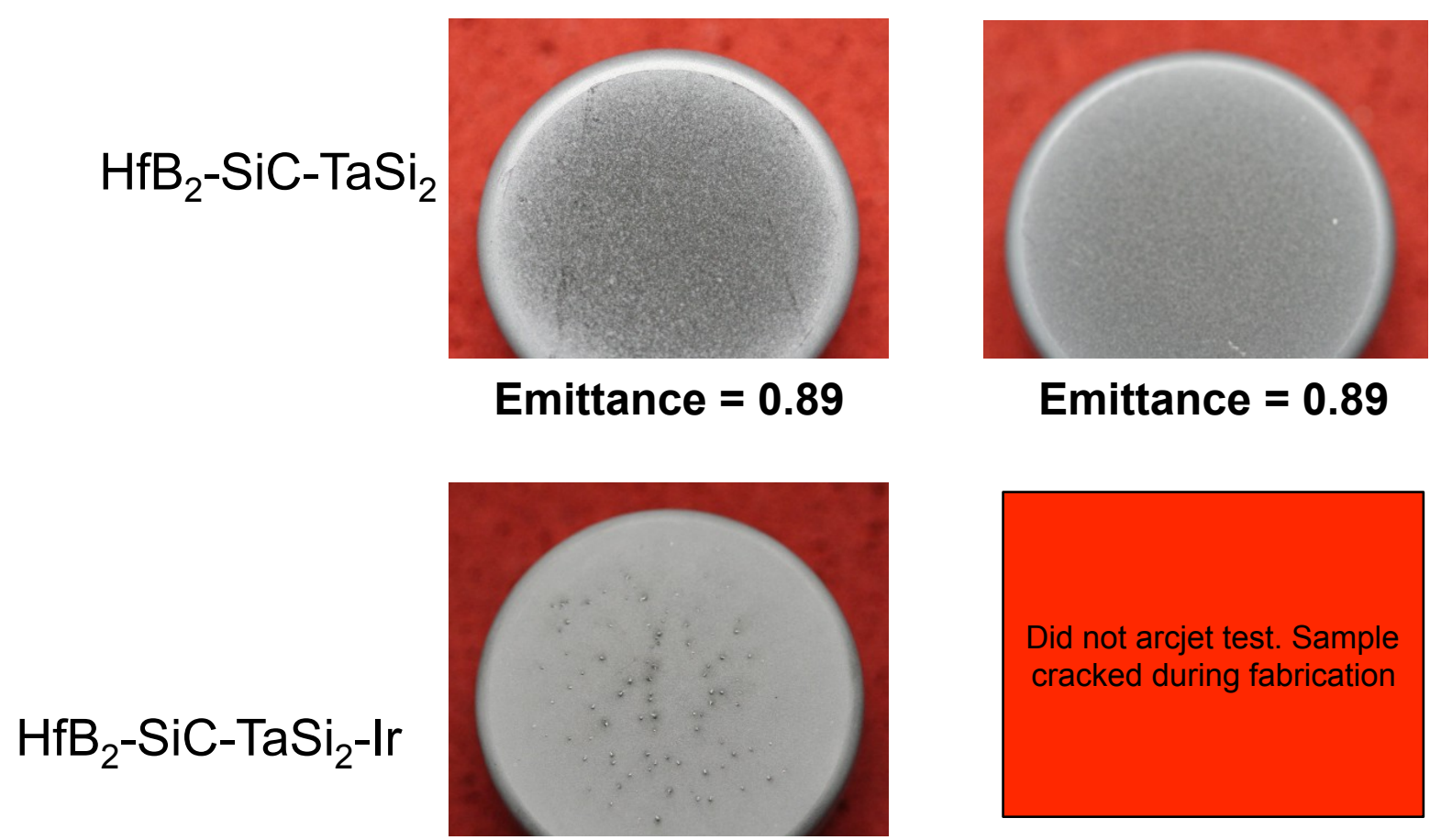

Emittance $=0.87$ 


\section{Arcjet Characterization}

\section{$\mathrm{HfB}_{2}-\mathrm{SiC}-\mathrm{TaSi}_{2}-\mathrm{Ir}$}

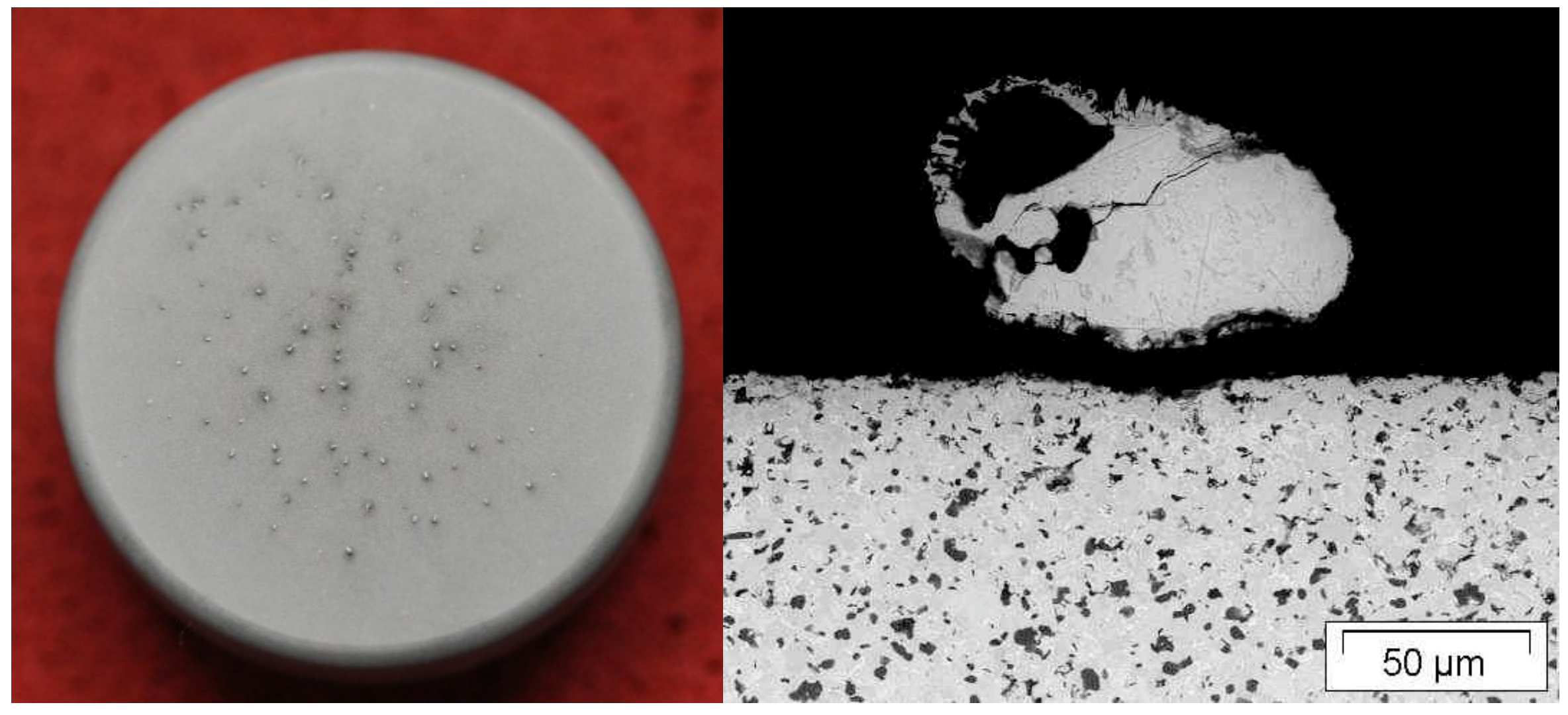

Close up of arcjet model with iridium, showing surface accumulation of Ir and corresponding SEM cross section 


\section{Arcjet Characterization: Cross Section}

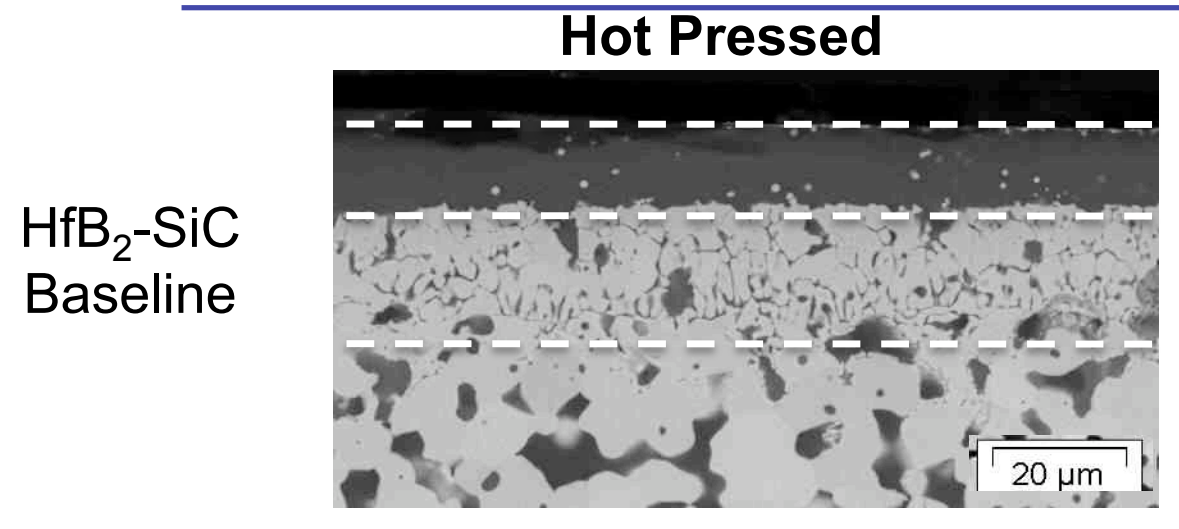

\section{Field Assist Sintered (FAS)}

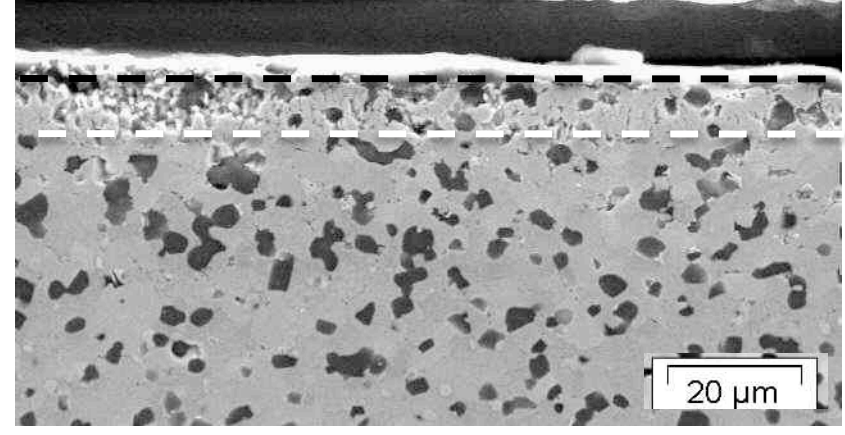

$\mathrm{HfB}_{2}-\mathrm{SiC}-\mathrm{TaSi}_{2}$
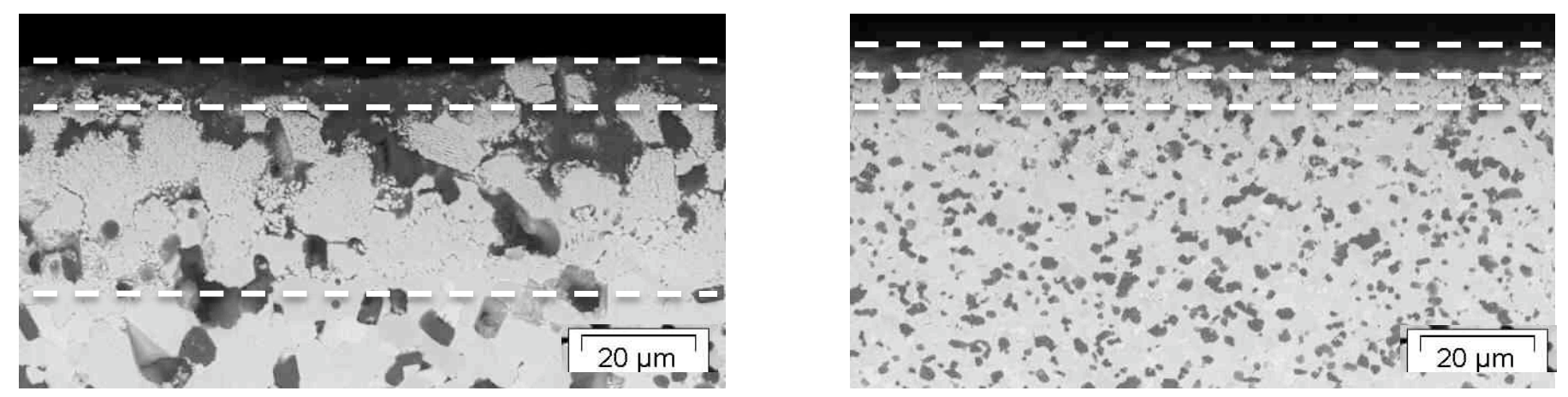

$\mathrm{HfB}_{2}-\mathrm{SiC}-$ $\mathrm{TaSi}_{2}-\mathrm{Ir}$
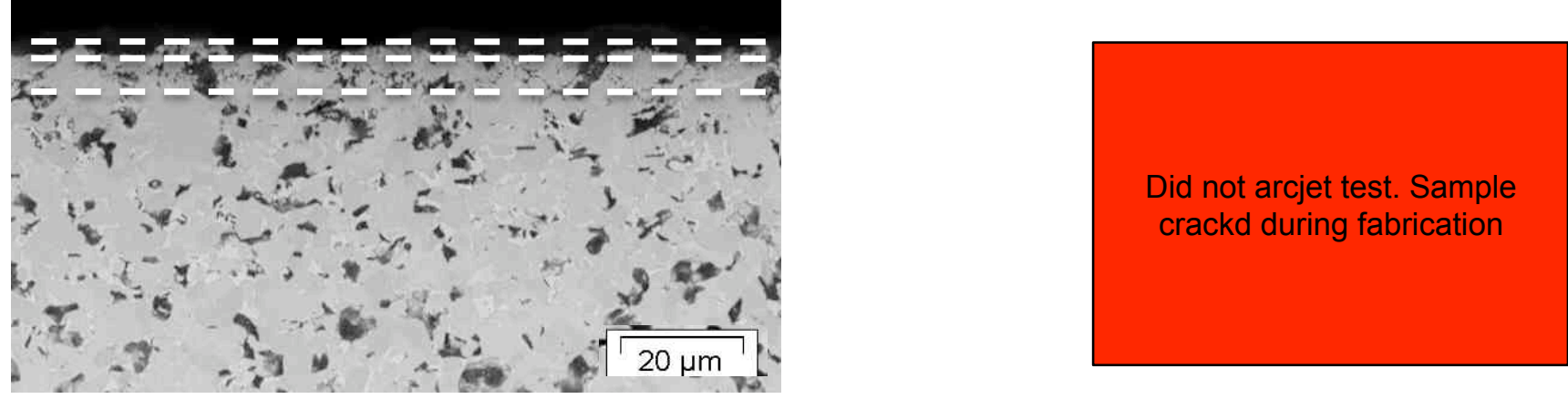


\section{Arcjet Characterization: Summary}

- Additions of $\mathrm{TaSi}_{2}$ seem to improve oxidation resistance of coupons fabricated with either HP or FAS. However, the sample fabricated by HP has a large SiC depletion zone, similar to the baseline material.

- Samples processed with iridium showed improved oxidation resistance and much smaller SiC depletion zones, in comparison to the baseline.

\begin{tabular}{|l|l|c|c|c|c|c|}
\hline \multicolumn{1}{|c|}{ Model ID } & \multicolumn{1}{c|}{$\begin{array}{c}\text { Sinter } \\
\text { Method }\end{array}$} & $\begin{array}{c}\text { Heat Flux } \\
\left(\mathrm{W} / \mathrm{cm}^{2}\right)\end{array}$ & $\begin{array}{c}\text { Pstag } \\
(\mathrm{atm})\end{array}$ & $\begin{array}{c}\text { Duration } \\
(\mathrm{sec})\end{array}$ & $\begin{array}{c}\text { Oxide Layer } \\
(\mu \mathrm{m})\end{array}$ & $\begin{array}{c}\text { SiC Depletion } \\
(\mu \mathrm{m})\end{array}$ \\
\hline $\begin{array}{l}\mathrm{HfB} \\
(\mathrm{Bas}-\mathrm{SiC}\end{array}$ & Hot Press & 300 & 0.19 & 600 & 13 & 24 \\
\hline $\mathrm{HfB}_{2}-\mathrm{SiC}$ & FAS & 250 & 0.10 & 600 & 3 & 8 \\
\hline $\mathrm{HfB}_{2}-\mathrm{SiC}-\mathrm{TaSi}_{2}$ & Hot Press & 250 & 0.10 & 600 & 7 & 34 \\
\hline $\mathrm{HfB}_{2}-\mathrm{SiC}-\mathrm{TaSi}_{2}$ & FAS & 250 & 0.10 & 600 & 3 & 6 \\
\hline $\mathrm{HfB}_{2}-\mathrm{SiC}-\mathrm{TaSi}_{2}-\mathrm{Ir}$ & Hot Press & 250 & 0.10 & 600 & 4 & 9 \\
\hline
\end{tabular}


Microstructure / Composition Affects Oxidation Behavior

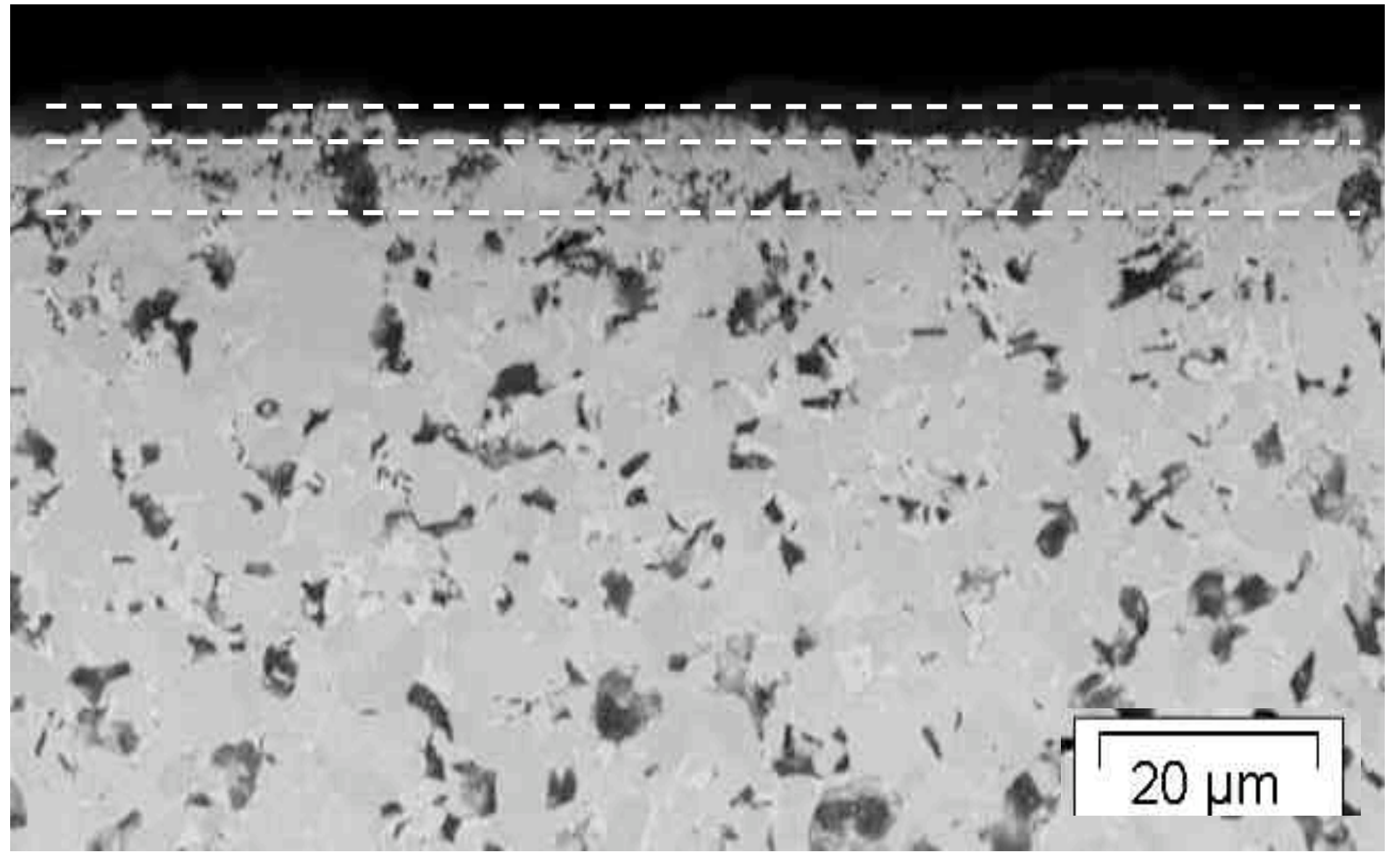

$\mathrm{HfB}_{2}-\mathrm{SiC}-\mathrm{TaSi}_{2}-$ Ir (Post-Test) 


\section{Some Recent Work}

- Experimental effort

- Initially focused on optimizing matrix - UHTC or other high-temperature fibers not available

- Presently includes investigation of UHTC fiber composites - currently NASA has SBIRs with companies to develop UHTC fibers

- Computational effort - modeling to better optimize microstructure / properties 


\section{Formation of Carbide Coatings on C Fibers}

- Metal chlorides to process refractory metal carbides on carbon substrates

- Initial efforts resulted in carbide formation ( $\mathrm{ZrC}, \mathrm{TiC}, \mathrm{TaC}$ and $\mathrm{HfC}$ ) and oxide formation - fiber degradation dependent on the metal chloride concentration

- Optimizing process for graded carbide coating on carbon fibers in weave

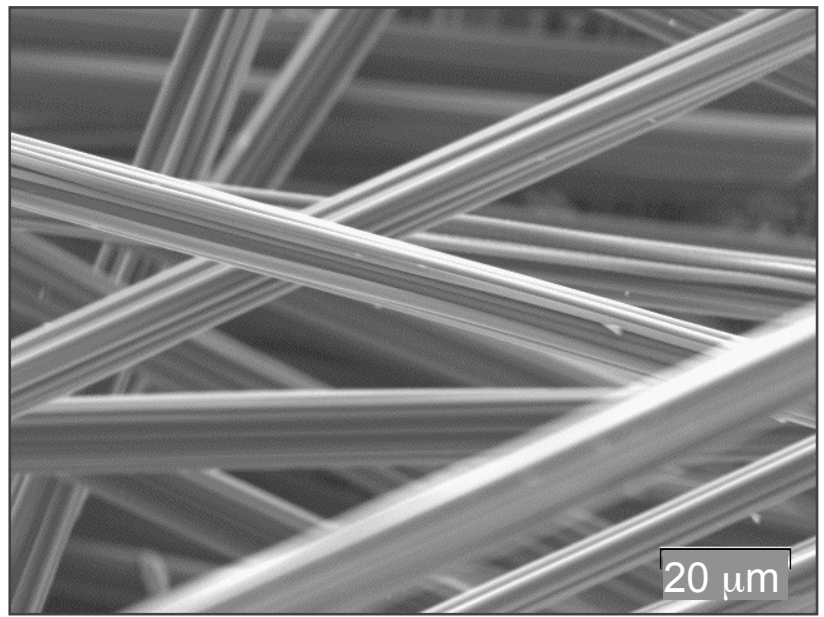

As received

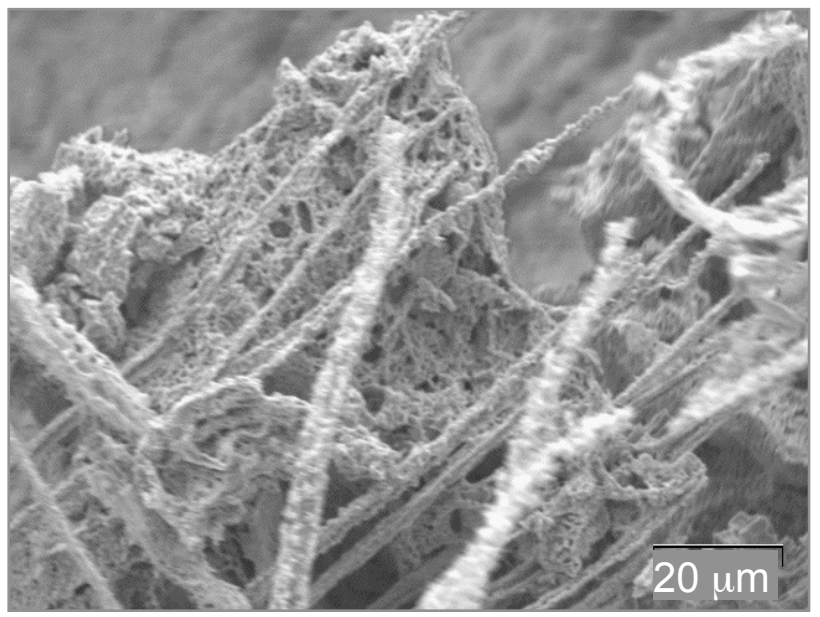

Treated with titanium chloride

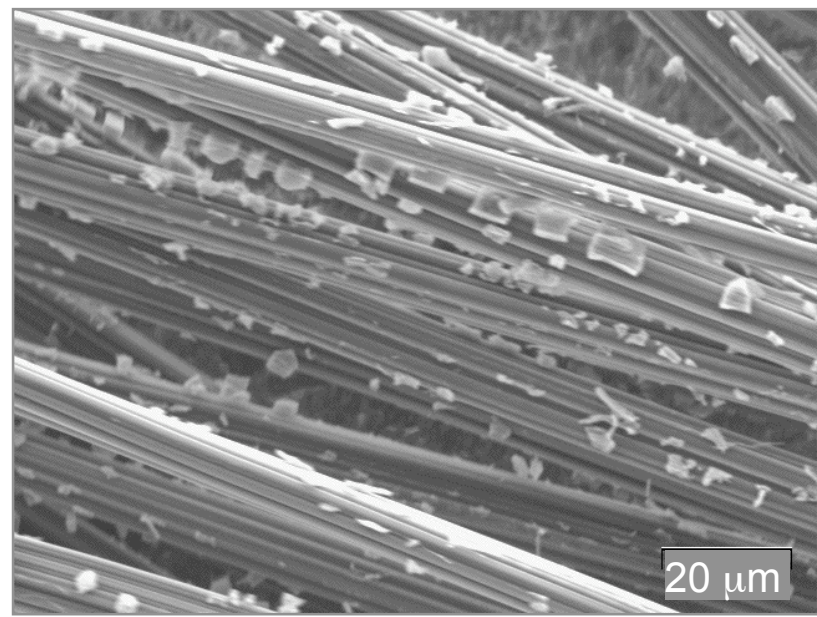

Treated with dilute titanium chloride 


\section{Formation of Carbide Coatings on C Fibers}

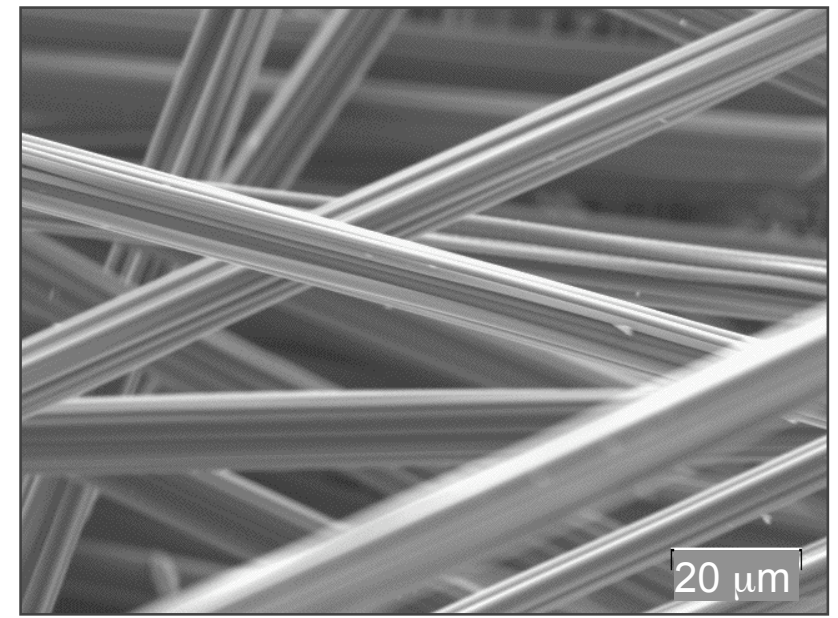

As received

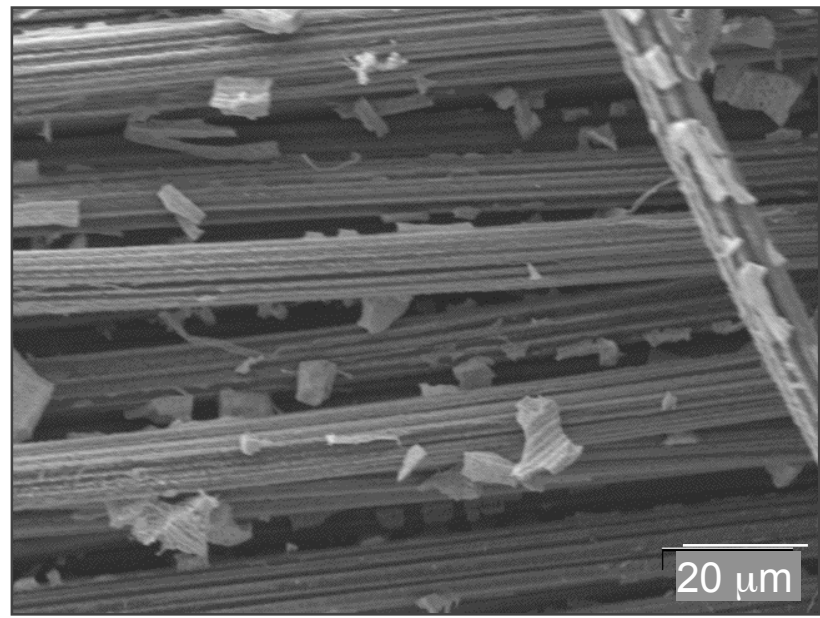

Treated with dilute hafnium chloride

- Formation of hafnium carbide / oxide on C fibers demonstrated

- These weaves could potentially be used in continuous fiber composites 


\section{Ultra High Temperature Continuous Fiber Composites}

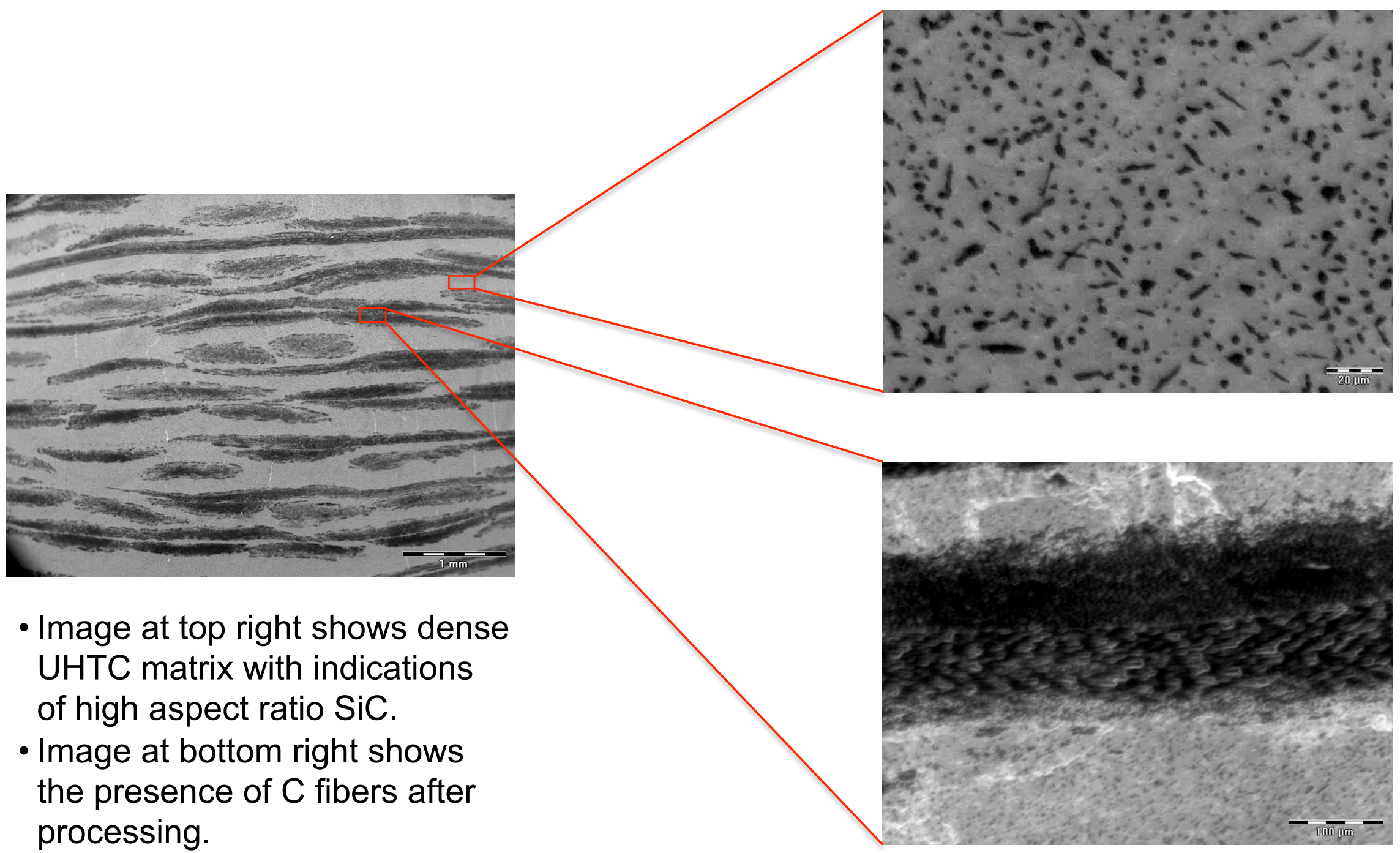




\section{FEM Modeling of UHTC Microstructure}

- How does morphology of microstructure affect material properties?

- Joint experimental / modeling project including materials modelers, FEM modelers, and experimentalists: Thermal and mechanical FEM calculations based on 2D images
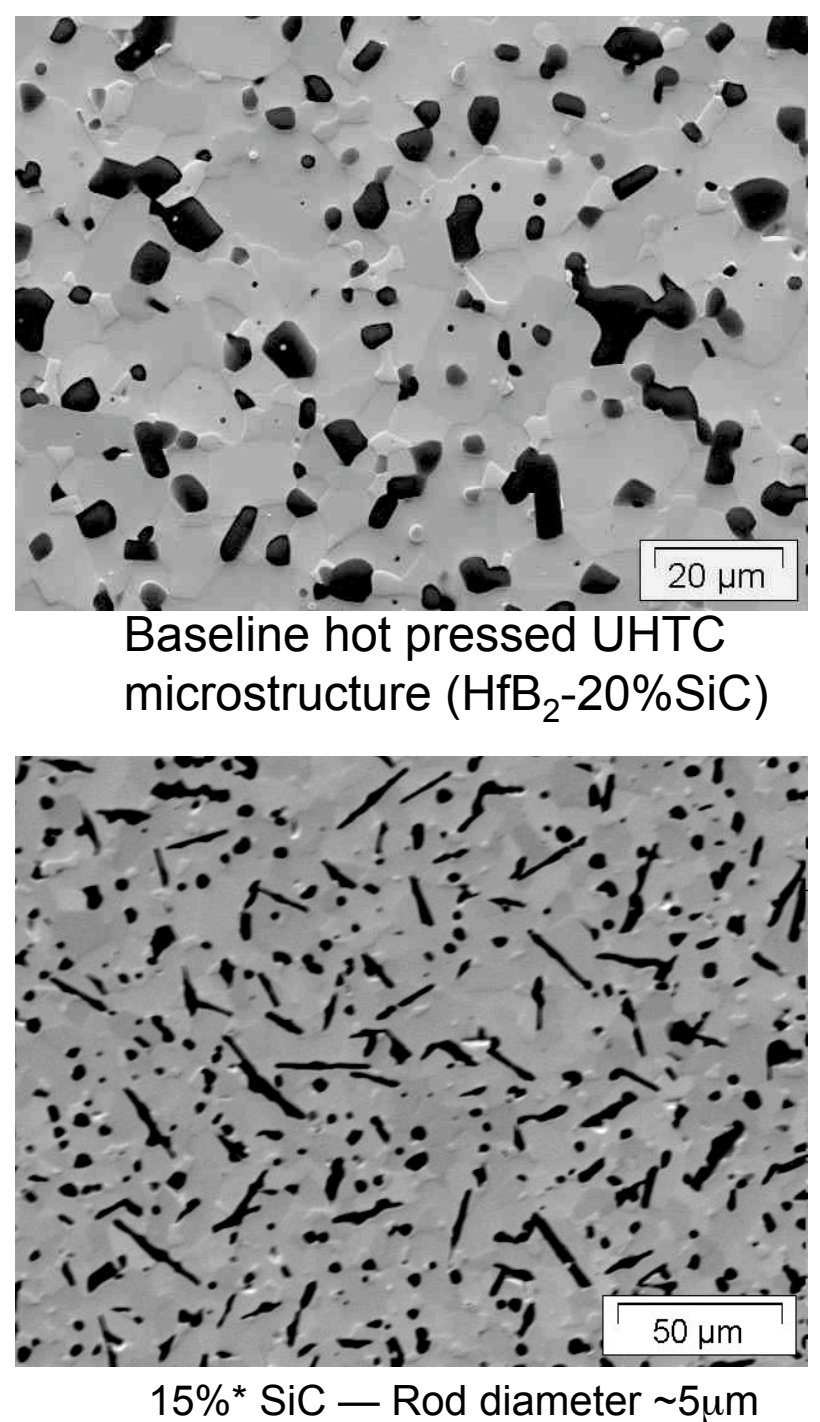


\section{Computational Modeling Architecture for UHTCs}

- Image-based FEM - grain structure effect on mechanical \& thermal properties using 3D imaging of real structures

- Atomistic simulations (molecular dynamics) - mechanisms at individual interfaces and defects and impact on properties

- Interatomic potentials (Clemson Univ)

- Thermal transport

- Dislocations/plastic deformation

- GB adhesion

- Crack propagation/toughness

- Impurities in GB

- $\quad A b$ initio calculations - intrinsic properties of material (inside grain)

- Crystal structure and interatomic bonding

- Elastic constants

- Electronic structure (DOS, band structure)

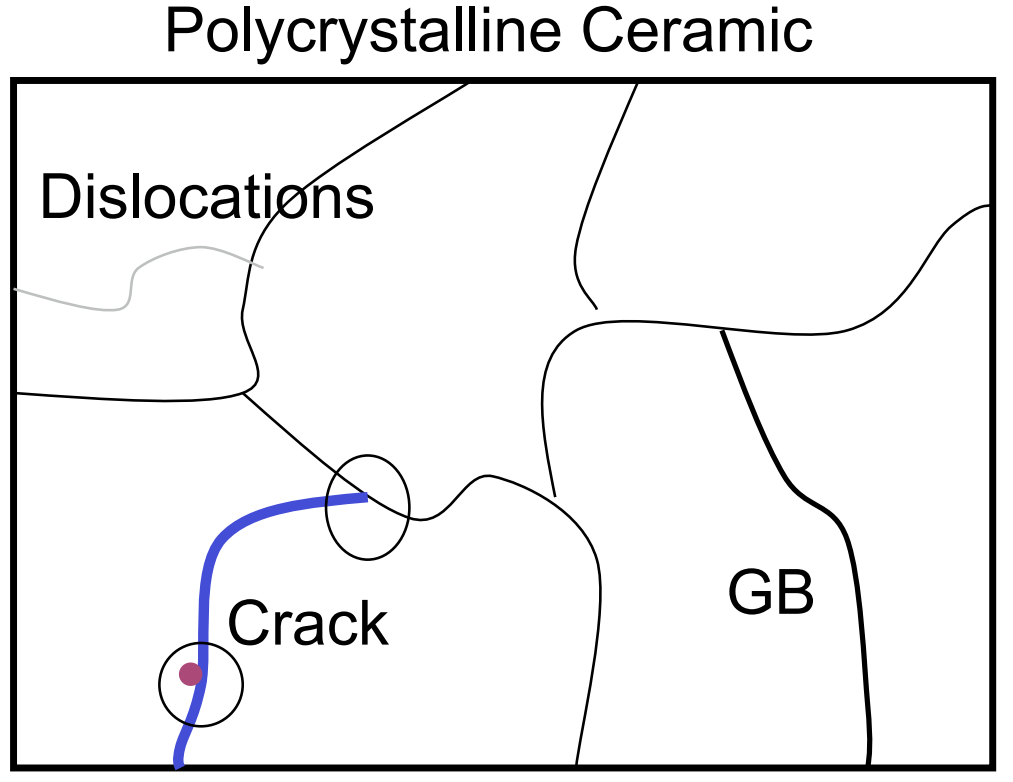

Impurities in grain boundaries

- Optical properties (reflectivity, absorption)

- Vibrational spectra

- IR spectra and emissivity 


\section{Ab Initio UHTC Calculations}

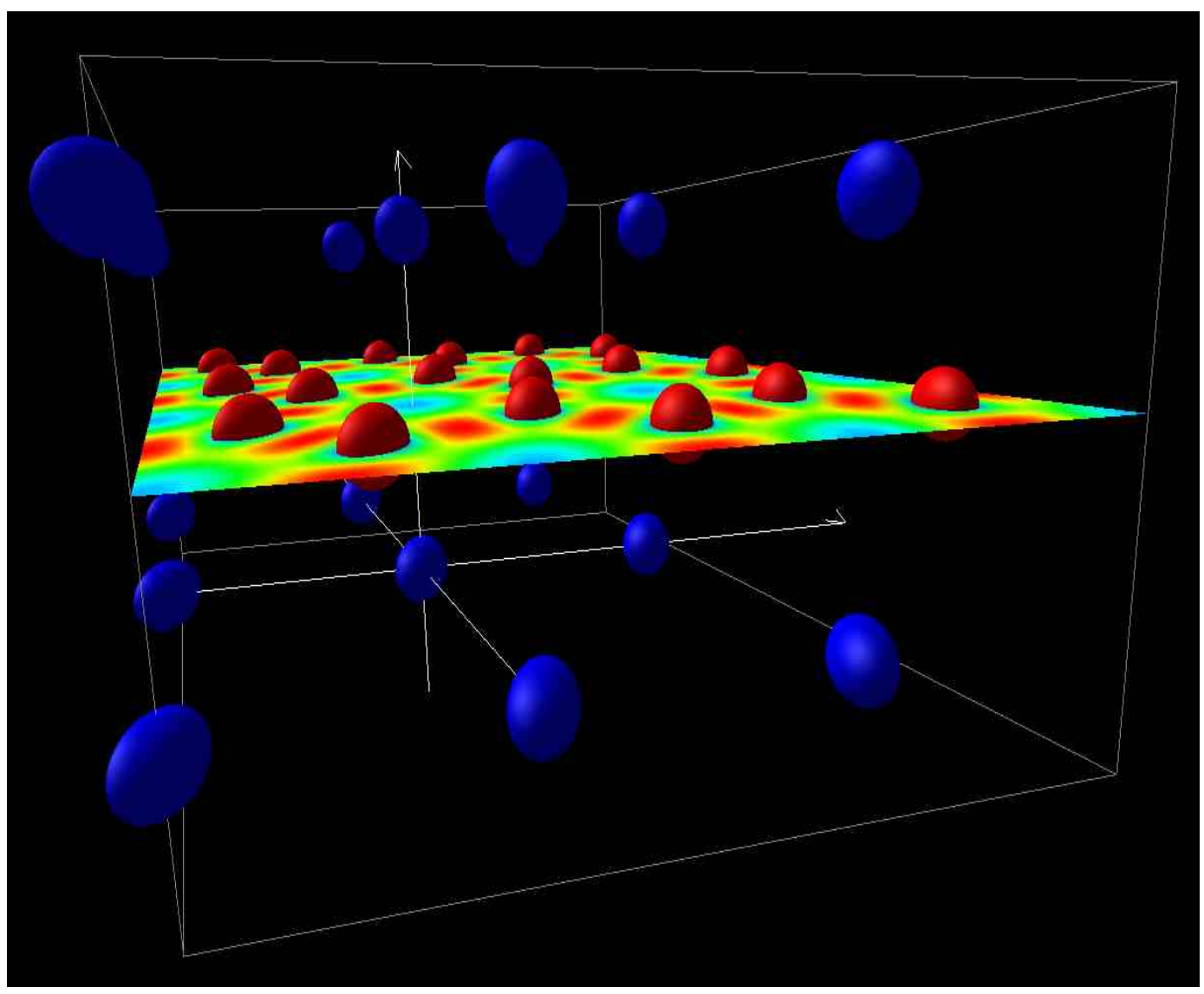

Lattice constants from fits to calculated potential energy curves. Values of $a=3.18$ angstroms and $c / a=1.11$ for the lattice constants are in excellent agreement with experiment.
Lattice Constant (a) vs Energy: ZrB2

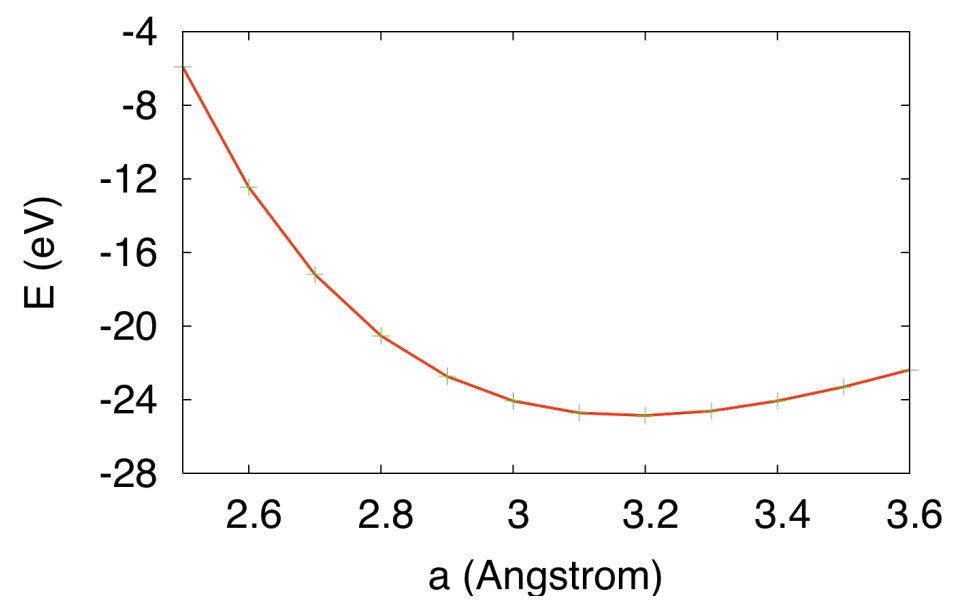

Lattice Constant (c/a) vs Energy: ZrB2

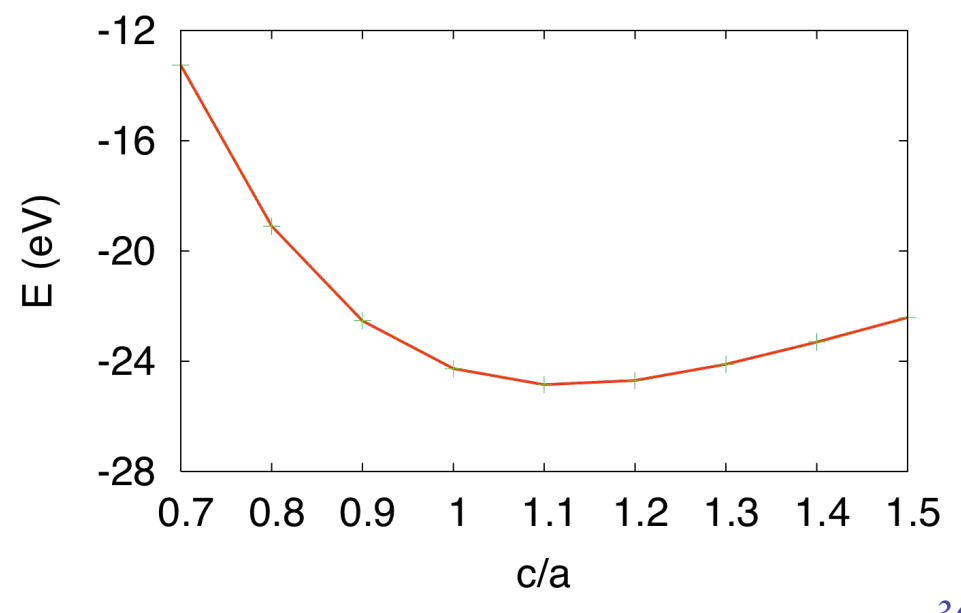




\section{Electronic Structure and Bonding}

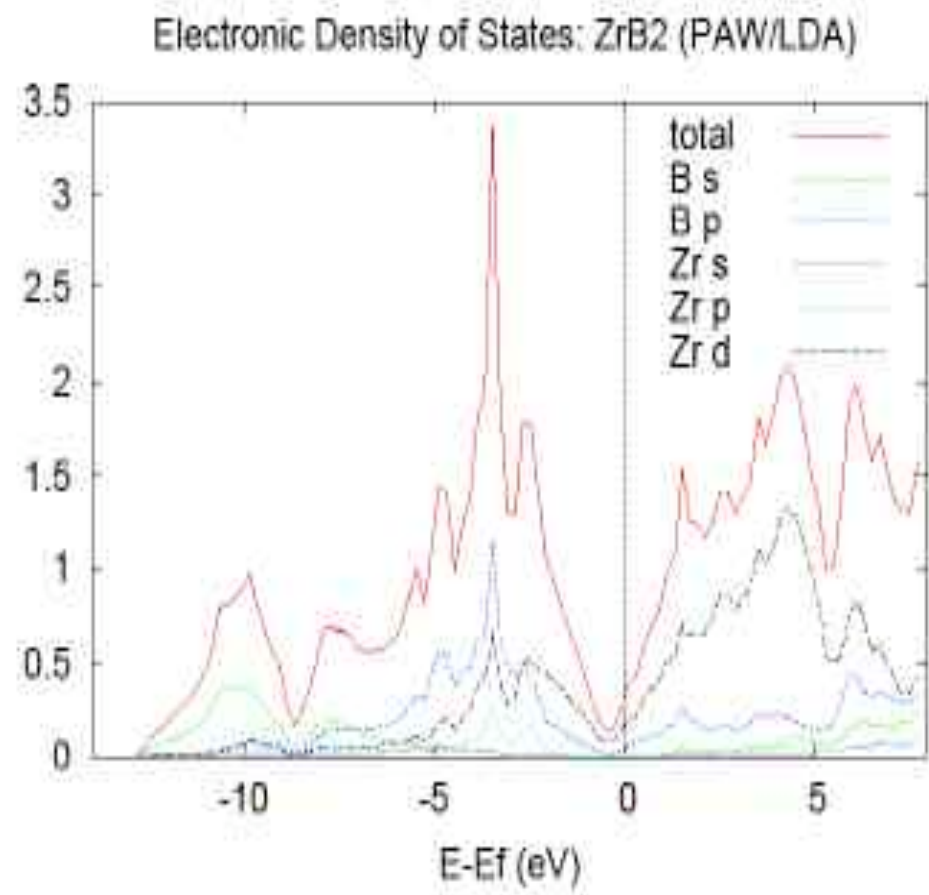

- Diborides are semi-metals with small density of states at Fermi level

- At Fermi level dominant bonding is hybridization of $\mathrm{B} p$ orbital and $\mathrm{Zr} d$ orbital

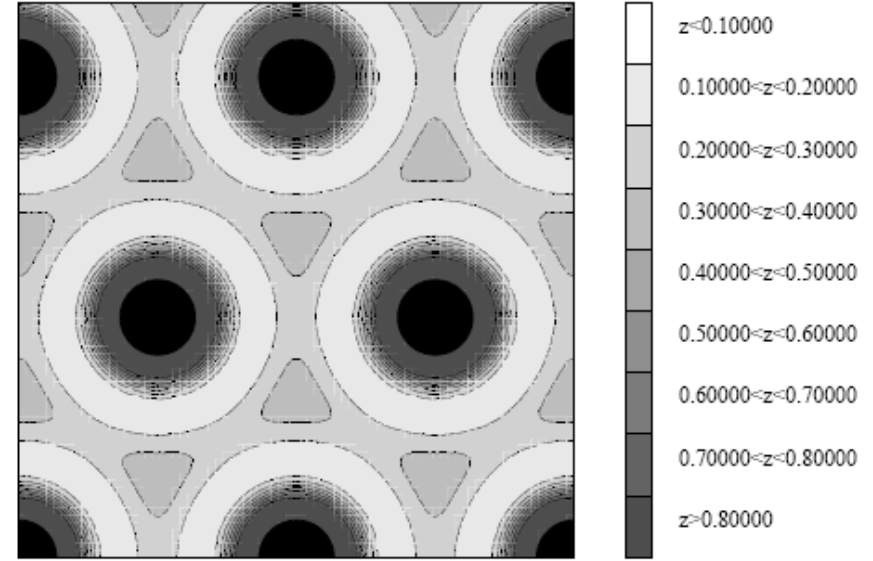

Zirconium plane: metallic bonding

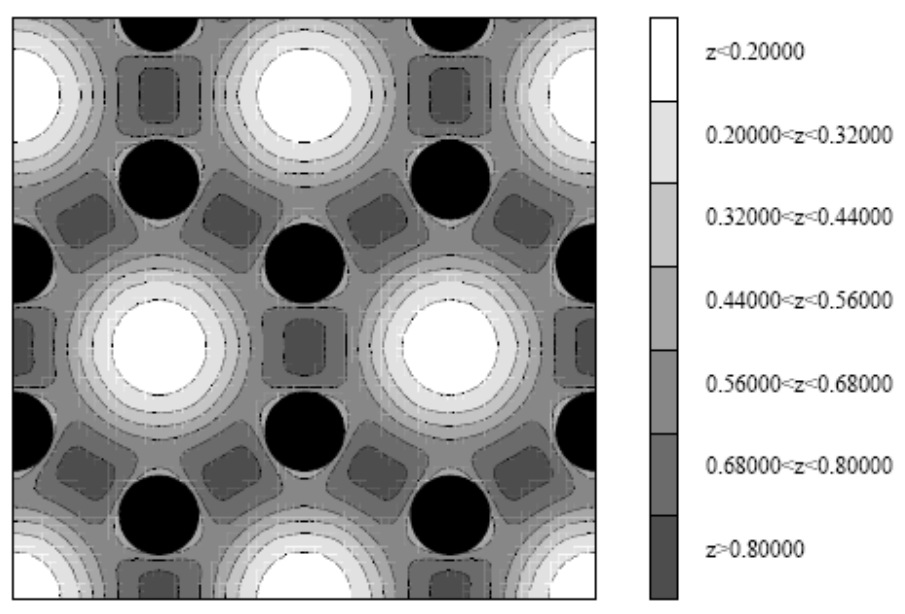

Boron plane: covalent bonding 


\section{Development of UHTC Atomic Potentials}

- Atomistic simulations for larger scale properties (mechanical, thermal, interfaces, defects) require interatomic potential

- Potentials for UHTCs do not currently exist - we must develop our own

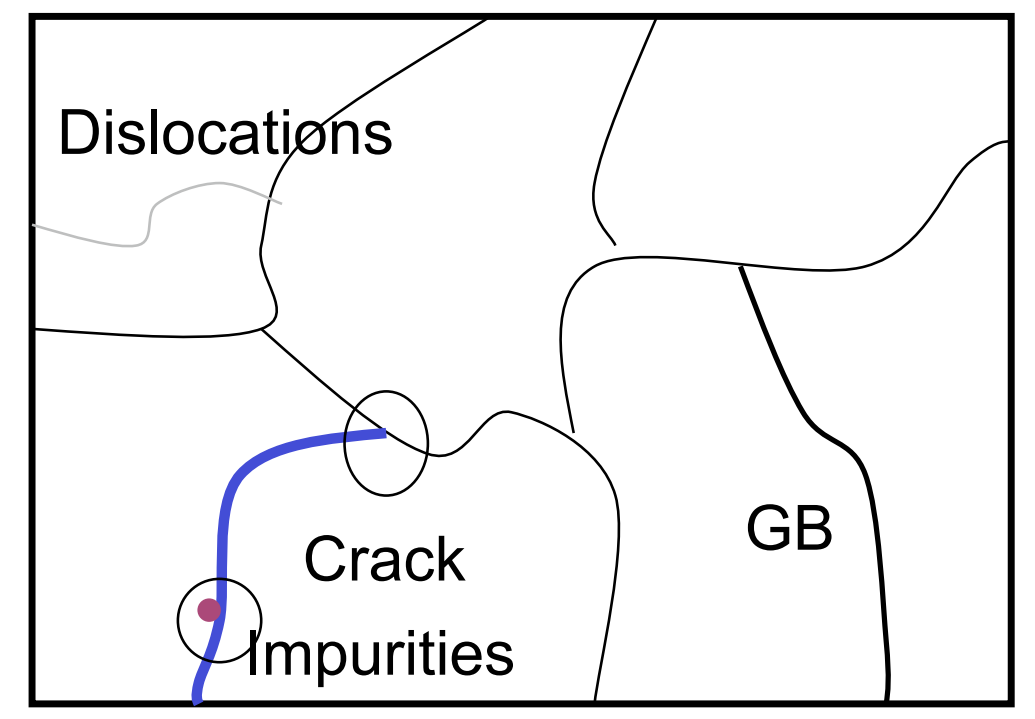

- Results from extensive $\boldsymbol{A b}$ Initio calculations will be fit to standard potential forms

- Collaboration with Murray Daw (Clemson University) and Charlie Bauschlicher 


\section{Imaged-Based Finite Element Modeling}

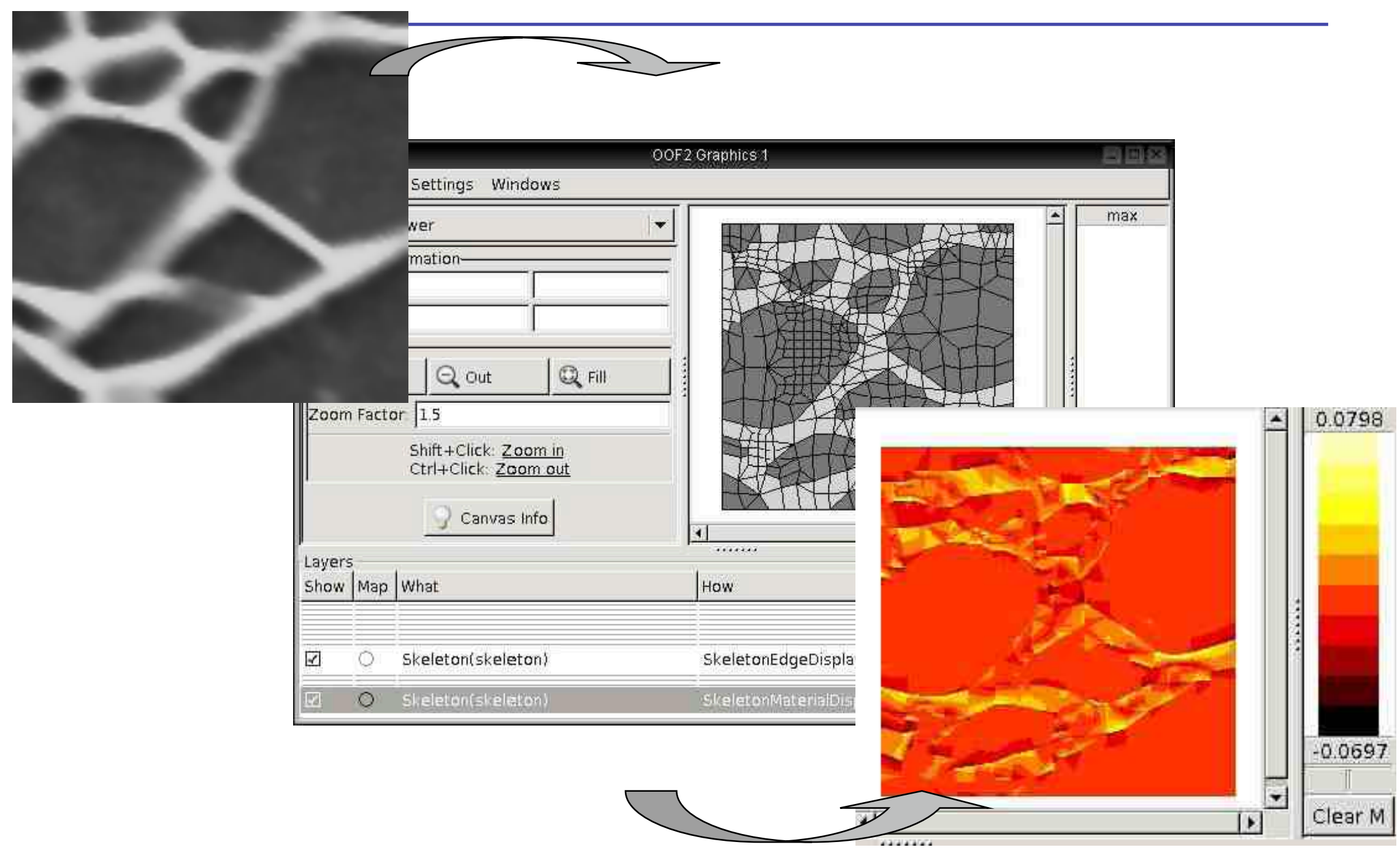

OOF: read image, construct mesh, FEM thermal and mechanical calculation 


\section{D Structures and FEM Modeling}

- 3D X-ray tomography images

- Virtual material

- Digitally manipulated and analyzed

- Collaboration with Xradia Corp

- 3D thermal \& mechanical FEM analysis

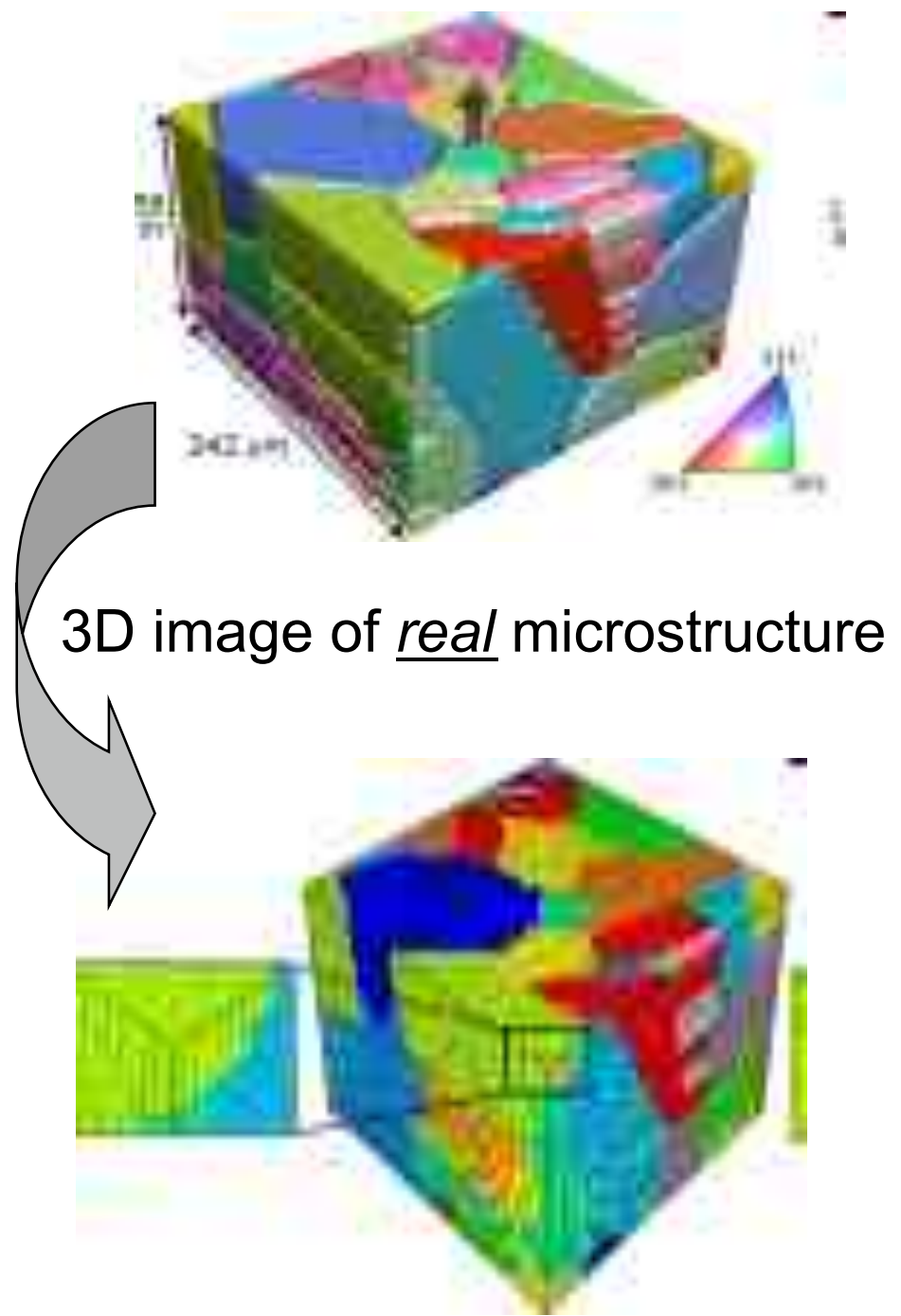

FEM mesh of realistic structure 


\section{Summary}

- Have investigated number of methods to control microstructure. We have routes to form:

- in situ "composites"

- Very fine microstructures

- High purity grain boundaries

- Arcjet testing and other characterization of monolithic materials

- Beginning to incorporate these materials as matrices for composites

- Initiating modeling effort to facilitate material design and characterization

- Continuing small effort in compositional microstructure variants 